

\title{
Molecular-dynamics simulations of binary Pd-Si metal alloys: Glass formation, crystallisation and cluster properties
}

\author{
Muhammad Faruq, Antoine Villesuzanne, Guosheng Shao
}

\section{To cite this version:}

Muhammad Faruq, Antoine Villesuzanne, Guosheng Shao. Molecular-dynamics simulations of binary Pd-Si metal alloys: Glass formation, crystallisation and cluster properties. Journal of Non-Crystalline Solids, 2018, 487, pp.72-86. 10.1016/j.jnoncrysol.2018.02.016 . hal-01794193

\section{HAL Id: hal-01794193 \\ https://hal.science/hal-01794193}

Submitted on 17 Feb 2021

HAL is a multi-disciplinary open access archive for the deposit and dissemination of scientific research documents, whether they are published or not. The documents may come from teaching and research institutions in France or abroad, or from public or private research centers.
L'archive ouverte pluridisciplinaire HAL, est destinée au dépôt et à la diffusion de documents scientifiques de niveau recherche, publiés ou non, émanant des établissements d'enseignement et de recherche français ou étrangers, des laboratoires publics ou privés. 


\title{
Molecular-dynamics simulations of binary Pd-Si metal alloys: Glass formation, crystallisation and cluster properties
}

\author{
Muhammad Faruq ${ }^{\mathrm{a}}$ Antoine Villesuzanne ${ }^{\mathrm{ab}}$ Guosheng Shao $^{\mathrm{ac}^{*}}$ \\ ${ }^{a}$ Institute for Renewable Energy and Environmental Technologies, University of Bolton, Bolton BL35AB, UK \\ ${ }^{b}$ CNRS, ICMCB, University of Bordeaux, F-33600 Pessac, France \\ 'UK-China Centre for Multi-functional Nanomaterials, Zhengzhou University, Zhengzhou 450001, People's Republic of China \\ *Corresponding author at: UK-China Centre for Multi-functional Nanomaterials, Zhengzhou University, Zhengzhou 450001, \\ People's Republic of China. / gsshao@zzu.edu.cn
}

\begin{abstract}
Using Quantum Sutton-Chen potentials, Molecular Dynamics was used to obtain an atomistic description of melting, glass formation and crystallisation processes for palladium metal, metallic silicon and their alloys, from $\mathrm{PdSi}$ to $\mathrm{Pd}_{5} \mathrm{Si}$. Glass formation and crystallisation were investigated using different cooling rates, by analysing the radial distribution function, enthalpy, density, volume, and diffusion coefficient. As expected, glass forms at high cooling rates, while crystallisation occurs at slower rates. The glass transition temperature was estimated from the Wendt-Abraham parameter vs temperature curves and the splitting of peaks in the radial distribution function. The effect of the $\mathrm{Pd} / \mathrm{Si}$ ratio on the glass transition was studied by analysing the volume change during cooling of the $\mathrm{Pd}$-Si alloys. The glass forming ability was found to increase with increasing Pd concentration in the alloys. Overall, our results reveal that Quantum Sutton-Chen potentials allow good descriptions of the melting, glass transition, and crystallisation during the heating and cooling processes.
\end{abstract}

Keywords: Metallic glass ; Quantum Sutton-Chen potentials ; Liquid-glass transition ; Glass formation and crystallisation ; Molecular dynamic simulation

\section{Introduction}

Cooling rate plays an important role in the amorphisation of a material. When a liquid metal is cooled to a low temperature from melt, depending on the cooling rate, either crystalline or amorphous structures can be obtained. If the cooling rate is greater than the critical cooling rate or sufficiently high, homogeneous nucleation of crystalline phases can be avoided, and metastable amorphous/glass structure is formed. Metallic glasses were first reported by Duwez and colleagues [1] in 1960, wherein they demonstrated the preparation of $\mathrm{Au}_{75} \mathrm{Si}_{25}$ metallic glass by rapid quenching of the $\mathrm{Au}_{75} \mathrm{Si}_{25}$ liquid to avoid the crystallisation of the alloy. Recently, a significant attraction in metallic-glass research has been assumed to the essential factors that play a role in glass formation [2]. For pure metals, the theoretical glass transition temperature is taken as $T_{g}=0.25 T_{m}$ ( $T_{m}$ is the melting temperature), whereas for various glass-forming metallic alloys, it has been observed experimentally that $\mathrm{T}_{\mathrm{g}}$ varies from 0.5 to $0.8 \mathrm{~T}_{\mathrm{m}}$ [3]. Accordingly, the structural changes in the liquid that occur during the cooling process are small and therefore, the transformation from the liquid into the amorphous solid phase can be investigated by examining atomic motions [4]. It is noteworthy that determining the nature of the glass formation from experiments is a rather difficult task.

Molecular dynamics (MD) can provide important insights into such complex processes by allowing the determination of quantities that are difficult to assess in real experiments and/or beyond the reach of first-principles methods. Currently, MD is one of the most powerful tools for investigating the glass formation and crystallisation processes of liquids on the atomic scale. Moreover, it is reliable for the study of short-range structural order in amorphous and glassy semiconductors. The first ab initio MD (AIMD) 
effort was made by Car and Parrinello [5], who adopted the so-called plane wave MD method to study the short-range order in amorphous silicon. Subsequently, the investigation of metallic glasses has turned into the foremost areas of MD simulation.

MD interest in metallic glasses covers various properties, such as statistic structures (i.e. pair correlation function) and transport (i.e. diffusion and viscosity) properties. Until the 19th century, the metalloid was referred to originally as non-metals or semi-metals. The term "metalloid" was reported initially by Pinkerton in 1800, to depict a mineral group of pyroxene with metallic magnificence [6]. Extension of the MD simulations into metal-metalloid systems are more challenging due to the complexity of describing the interaction potentials associated with directionality. In addition to successful MD simulation using Quantum Sutton Chen (Q-SC) potential of various metals and metallic alloys, e.g. face-centred-cubic (FCC) metals palladium, nickel, copper, silver and their binary alloys [[7], [8], [9]], more recently, efforts have been made to study the physical and structural properties of metalloid elements and their alloys with metals; for example, Silicon [10] and Pd-Si alloys [[11], [12], [13]]. In 1988, Stillinger and Weber (SW) [14] developed a new potential model to describe the interactions in solid and liquid forms of silicon. The outcome had revealed the structural and thermodynamic properties of amorphous silicon, which concurred with experimental data. To obtain an in-depth analysis of the disordered silicon phases along with its structural properties, "ab initio" MD study was conducted by Car and Parrinello, wherein an amorphous silicon was prepared by rapid cooling from the melt [15]. The results predicted during the simulation studies were in line with the observed experimental data.

Recently metalloid alloys such as silicon-germanium (SiGe) [16], have been studied using AIMD to investigate their structural and electronic properties. The results indicated that the total pair correlation function for the amorphous phase of silicon germanium (a-SiGe) was in line with the experimental data. It was demonstrated that the metallic character of the liquid phase of silicon germanium (I-SiGe) by evaluating its conductivity and derived semiconductor nature for the amorphous phase (a-SiGe). To extend MD systems for the metal and metalloid alloys, such as $\mathrm{Pd}_{80} \mathrm{Si}_{20}$, studies were conducted using the Yukawa pair potentials by Takagi et al. [11]. These revealed that a similar structural factor was found as observed in the experimental data obtained by Takagi et al., and the same number of the nearest neighbours of Pd around Si as the Gaskell proposed a structural model [13]. MD simulation for various PdSi alloy compositions using the Lennard-Jones pair potentials [11] investigated the local atomic structure based on the analysis of Voronoi polyhedra, which demonstrated that the medium range order (MRO) increased rapidly, as the composition of Si decreased.

Since the 1980s, great achievements have been made in the formulation of the interatomic potential with the consideration of some many-body effect with the inclusion of volume or density dependence to describe metallic bonding; for example, the effective medium theory [17], the embedded atom method (EAM) [18], Finnis-Sinclair (FS) [19] and Sutton-Chen (SC) [20] type potentials. In fact, Sutton-Chen potentials have been used widely due to their simple mathematical formulation and long-range characteristics; in particular, they have been used successfully in MD studies of thermal and mechanical properties of transition metals and metal alloys. In addition, Quantum Sutton-Chen potentials (Q-SC) [7], which involves parametrisation from fitting to first-principles properties, were used successfully in various investigations of metallic systems; glass formation, crystallisation, surface phenomena, clusters, nanowires, single crystal plasticity and transport properties.

Owing to better reproducibility of metallic systems properties with QC potential over the simpler pairpotential, Kart et al. [21] studied melting, cooling, and crystallisation of binary $\mathrm{Pd}_{\mathrm{x}} \mathrm{Ag}_{1-\mathrm{x}}$ alloys, and they obtained a wide range of accurate values for physical properties of the liquid, crystal, and glass phases. The resultant Q-SC potentials provided a satisfactory prediction of temperatures for melting, glass transition, and crystallisation during heating and cooling processes. Various efforts were also made to 
study the metalloid silicon materials using classical potentials, such as the simple Lennard-Jones pair-wise potentials [12], three-body potentials [22], Stillinger and Weber, [14] Tersoff [23], and EAM potentials [24].

While many researchers have used the SC potentials to study $\mathrm{FCC}$ metals such as $\mathrm{Pd}, \mathrm{Cu}, \mathrm{Ni}, \mathrm{Ag}, \mathrm{Au}, \mathrm{Ir}, \mathrm{Pb}$, $\mathrm{Al}, \mathrm{Pt}, \mathrm{Rh}$ and their alloys, to the best of our knowledge, no one has previously attempted to use (Q-SC) to study metallic alloys containing Si. In this work, we have conducted a comprehensive study of the Pd-Si system; including its structural properties, glass transition \& crystallisation temperatures, transport properties and cluster properties of metallic glasses. Firstly, we have derived the Q-SC many-body potentials, and then applied them to simulate the important materials phenomena associated with cooling and heating, in the temperature range from 0 to $2000 \mathrm{~K}$.

\section{Computational details}

\subsection{Density functional theory calculations}

First-principle calculations, within density functional theory (DFT) and the generalised gradient approximation (GGA) for the exchange-correlation energy, as implemented in the Vienna Ab-Initio Simulation Package (VASP) code [25], were used to fit the Sutton-Chen potentials. The cohesive energy and lattice parameters of palladium, metallic silicon and their alloys were calculated using a $7 \times 7 \times 7$ Monkhorst-Pack grid [26] for the Brillouin zone sampling and a $300 \mathrm{eV}$ energy cut-off. The plane-wave basis sets energy cut-off, and k-point grid was selected to ensure energy convergence to less than 1 meV per atom. The total energy (E) of the crystal was calculated for a set of chosen volumes (V), and the resulting $E$ vs $V$ data was then fitted to an integrated 3rd-order Birch-Murnaghan equation-of-state (EOS) [27] to calculate the bulk modulus of the Pd-Si system. The GGA functional, used throughout this work, generally provides an accurate description of closed-packed, metallic and intermetallic systems [28]. Electronic properties (transport, magnetism) might require a more accurate treatment of non-local effects (correlation, exchange) in some cases, but are not within the scope of the present work.

\subsection{Derivation of interatomic potentials}

The DLPOLY MD package [29], along with Q-SC potentials, were used to gain insights into melting and solidification processes at the atomic scale. Çağin et al. [8] to reproduce experimental properties such as density, cohesive energy, bulk modulus, and phonon frequencies, while including zero-point energy (quantum) effects, first introduced quantum corrections to SC-type potentials by fitting them to DFT results. In the current research, Q-SC potential parameters for palladium and metallic silicon were obtained by fitting to some experimental data; for example, lattice parameters, cohesive energy, and bulk modulus.

The Sutton-Chen interaction potential comprises a pair potential $V\left(r_{i j}\right)$ between atoms $i$ and $j$, responsible for the Pauli repulsion between the core electrons, and a local energy density $\rho_{i}$ term accounting for the cohesive interactions with atom $\mathrm{i}$. The total potential energy takes the following form: 
$\mathrm{U}_{\text {tot }}=\sum_{\mathrm{i}} \mathrm{U}_{\mathrm{i}}=\sum_{\mathrm{i}}\left[\sum_{\mathrm{j} \neq \mathrm{i}} \frac{1}{2} \epsilon_{\mathrm{ij}} \mathrm{V}\left(\mathrm{r}_{\mathrm{ij}}\right)-\mathrm{c}_{\mathrm{i}} \epsilon_{\mathrm{ij}}\left(\mathrm{\rho}_{\mathrm{i}}\right)^{1 / 2}\right]$

where,

$V\left(r_{i j}\right)=\left(\frac{a_{i j}}{r_{i j}}\right)^{n_{i j}}$

and

$\rho_{i}=\sum_{j \neq i} \varnothing_{i j}\left(r_{i j}\right)=\sum_{j \neq i}\left(\frac{a_{i j}}{r_{i j}}\right)^{m_{i j}}$

In Eqs. (1), (2), (3), $r_{i j}$ is the distance between atoms $i$ and $j, a_{i j}$ is a length parameter leading to dimensionless $V\left(r_{i j}\right)$ and $\rho_{i} ; c_{i}$ is a dimensionless parameter scaling the attractive vs repulsive terms, $\epsilon_{i j}$ sets the overall energy scale, and $n, m$ are positive integers such that $n>m$. Interatomic terms $\epsilon_{i j}$ are derived from one-centre terms $\epsilon_{\mathrm{i}}$ and $\epsilon_{\mathrm{j}}$ according to:

$$
\epsilon_{\mathrm{ij}}=\sqrt{\epsilon_{\mathrm{i}} \epsilon_{\mathrm{j}}}
$$

$a_{i j}, m_{i j}$ and $n_{i j}$ interatomic terms are set as the arithmetic mean values of the corresponding one-centre terms.

In order to extract the parameter values, Rafii-Tabar and Sutton [30] have developed the so-called random binary fcc metal alloy method, wherein the two type of atoms randomly occupy the lattice sites with the required average concentration. Table 1 lists the Q-SC potential parameter values obtained from this method for Pd-Si alloys.

Table 1

Q-SC potential parameters for the Pd-Si system.

\begin{tabular}{llllll}
\hline Element & $\varepsilon(\mathrm{eV})$ & $\mathrm{a}(\mathrm{A})$ & $\mathrm{n}$ & $\mathrm{m}$ & $\mathrm{c}$ \\
\hline Pd-Pd & 0.003967 & 3.9382 & 12 & 7 & 113.14 \\
Si-Si & 0.064310 & 3.7653 & 6 & 5.25 & 12.76 \\
Pd-Si & 0.016304 & 3.8838 & 9 & 6.125 & - \\
\hline
\end{tabular}

\subsection{MD simulation details}

We performed constant-pressure and constant-temperature molecular dynamics simulations (NPT), based on the extended Hamiltonian formalism from the work of Andersen [31], Parrinello and Rahman [32], Nosé [33], and Hoover [34]. This scheme combines the Nosé canonical variable shape size and the Parrinello-Rahman variable shape size ensembles. NPT MD allows the study of phase transformations while permitting changes to the cell shape and size. The NPT simulations began from a box subject to periodic boundary conditions, for a system of 1000 to 1372 particles. Variations of energy with system sizes are small when the system sizes are chosen above 1000 atoms as shown in Fig. 1 for the $\mathrm{Pd}_{3} \mathrm{Si}$ 
supercell. The temperature was increased initially from $300 \mathrm{~K}$ to $2000 \mathrm{~K}$ in $100 \mathrm{~K}$ increments, at different heating rates ranging from $10 \mathrm{~K} / \mathrm{ps}$ to $1 \mathrm{~K} / \mathrm{ps}$. The system was run for 50,000 time steps at $2000 \mathrm{~K}$, in order to achieve an equilibrium liquid state as the initial configuration for the cooling process, which was conducted using NPT MD. The system was then cooled to room temperature with $100 \mathrm{~K}$ decrements, at different cooling rates ranging from $10 \mathrm{~K} / \mathrm{ps}$ to $1 \mathrm{~K} / \mathrm{ps}$. The simulation time step was chosen as $0.002 \mathrm{ps}$. The cut-off selected for our interaction potential at a range of two lattice parameters where the forces are trivial and the half of a lattice distance was also added to this range to consider the temperature effect. The macroscopic and microscopic features of the system, such as volume, enthalpy, glass transition, crystallisation temperature and cluster properties were obtained from the NPT MD cooling runs. Finally, additional steps of simulation were performed to investigate transport properties, such as diffusion.

\section{Results and discussion}

The Q-SC potentials for the Pd-Si system derived in this work are verified through MD calculation of structural properties for both elemental phases and binary alloys, as discussed in the earlier work by Faruq et al. [35]. The results for lattice constant, cohesive energy, and bulk modulus were in good agreement with the literature and experimental data. Based on the agreement between simulation results and literature data, it is interesting to describe the glass transition and crystallisation phenomena of Pd-Si metal alloys by MD.

\subsection{Glass formation and crystallisation}

Fig. 2 (a-d) illustrates the variation of cell volume and enthalpy of Pd-Si alloys as a function of temperature at different cooling rates. The enthalpy decreases linearly with temperature and no significant difference is observed in the enthalpy changes between different cooling rates above the melting/solidification points. Conversely, the cooling rate strongly affects the low-temperature region (i.e. below $900 \mathrm{~K}$ ). For the slowest cooling rates used in the simulation (i.e. $5 \mathrm{~K} / \mathrm{ps} \& 1 \mathrm{~K} / \mathrm{ps}$ ), the enthalpy values reveal a sharp break with the decreasing temperature; thus correlating to crystallisation. In contrast, when a faster cooling rate of $10 \mathrm{~K} / \mathrm{ps}$ was applied to simulate the cooling process, no drop in enthalpy was observed and only slight changes to the slope indicated a liquid to amorphous or glass transition. The $\mathrm{Pd}_{5} \mathrm{Si}_{\text {ICSD }}$ (ICSDInorganic Crystal Structure Database) system shows a glass formation tendency at temperatures of $730 \mathrm{~K}$ at fast cooling rates while crystallisation occurs at $650 \mathrm{~K}$ and $850 \mathrm{~K}$ at cooling rates between $5 \mathrm{~K} / \mathrm{ps}$ to $1 \mathrm{~K} / \mathrm{ps}$. 

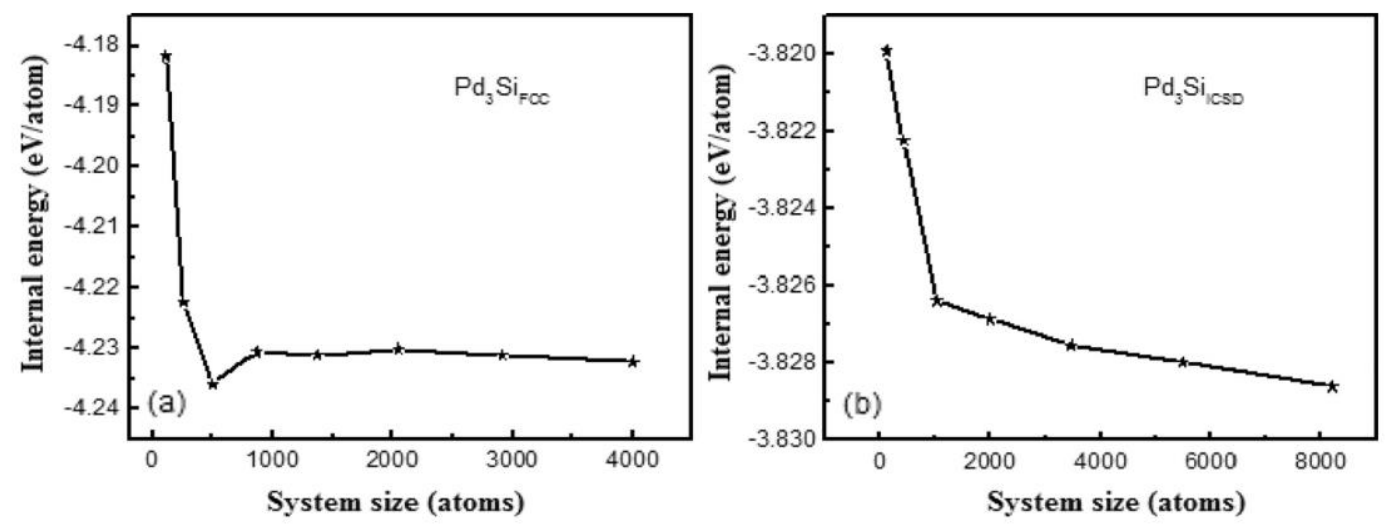

Fig. 1. Internal energy variations with system sizes (a) $\mathrm{Pd}_{3} \mathrm{Si}_{\mathrm{FCC}}$ (b) $\mathrm{Pd}_{3} \mathrm{Si}_{1 \mathrm{ICD}}$.
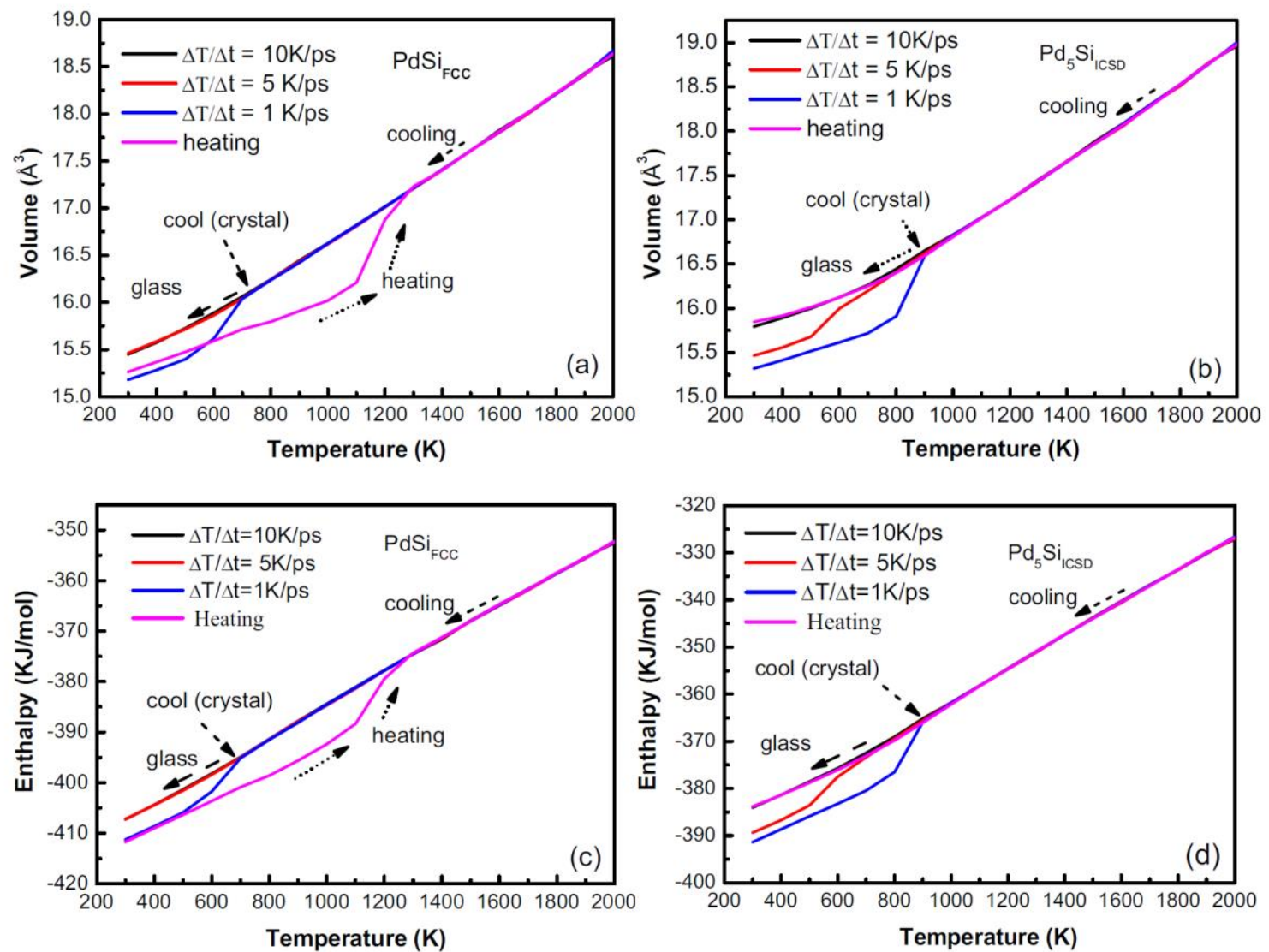

Fig. 2. Changes in volume and enthalpy during heating and cooling of $\mathrm{PdSi}_{\mathrm{FCC}}((\mathrm{a}) \&(\mathrm{c}))$ and $\mathrm{Pd}_{5} \mathrm{Si}_{\mathrm{CSD}}((\mathrm{b})$ \& (d)). [Note: FCC - Face centre cubic and ICSD - Inorganic Crystal Structure Database].

\subsection{Pair correlation function}

The pair correlation function $g(r)$ is defined as:

$$
g(r)=\rho^{-2}\left\langle\sum_{i} \sum_{j \neq i} \delta\left(r_{i}\right) \delta\left(r_{j}-r\right)\right\rangle
$$

where $g(r)$ is the probability of finding an atom at a distance $r$ from the reference atom located at the origin, considering an average density $\rho$. This function can be extracted from $X$-ray and neutron diffraction experiments [36]. Moreover, $g(r)$ can be computed from atomic trajectories in MD. As illustrated in Fig. 3, 
sharp peaks can be observed for crystalline phases (black line) and broad hillocks in liquids (green line); secondary hillock splitting characteristic of an amorphous structure (blue line).

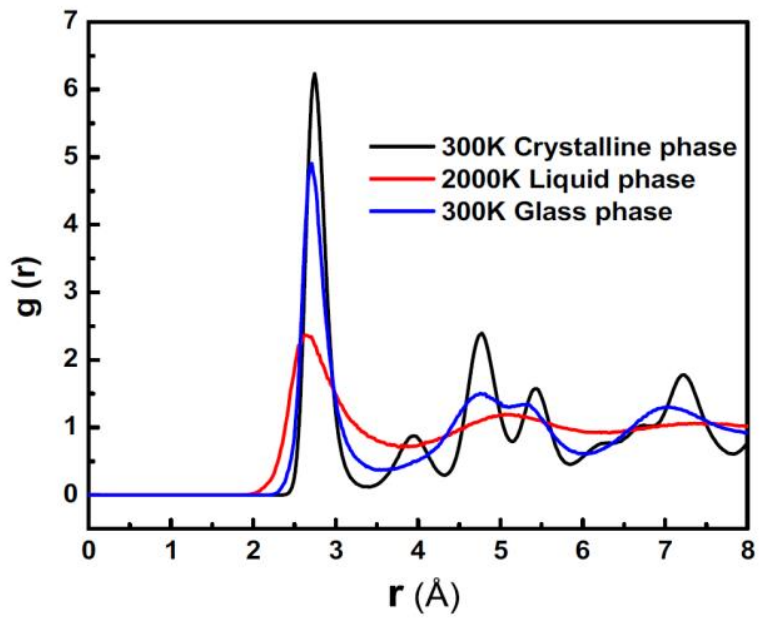

Fig. 3. Pair correlation function for different phases of $\mathrm{PdSi}_{\mathrm{FCC}}$ alloy during heating and cooling at $10 \mathrm{~K} / \mathrm{ps}$.

The evolution of structural changes can also be explicitly depicted through trajectory records of structural configurations, such as these shown in Fig. 4 in snapshots of simulated PdSi structures: regular configurational pattern for a crystalline structure (Fig. 4a), liquid disorder structure with clustering tendency within the same elements, either Pd or Si (Fig. 4b), and disordered structure with clustering tendency between cross elements (Fig. 4c) for glass structure.

(a) Solid crystalline state at $300 \mathrm{~K}$

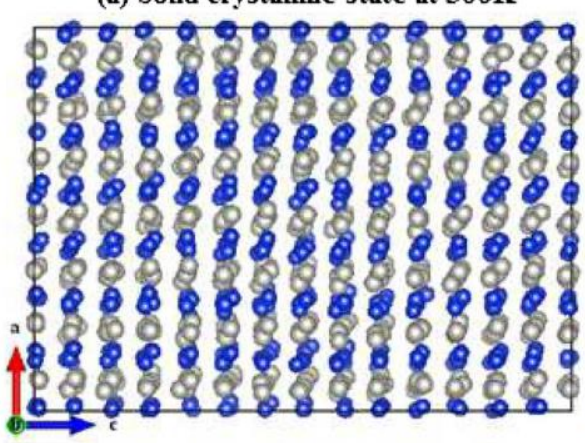

(b) Liquid state at $2000 \mathrm{~K}$

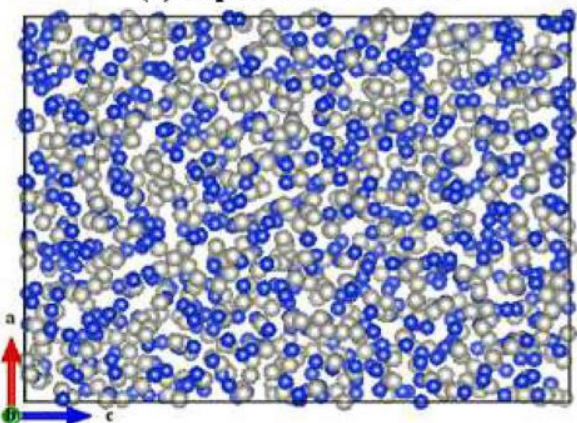

(c) Glass at $300 \mathrm{~K}$

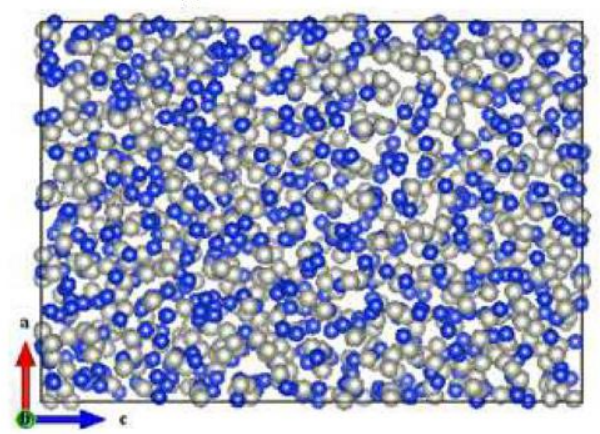

Fig. 4. Snapshot of atomic structure for crystalline state (a), liquid state (b, containing short range order), and glass state (c, containing medium range order) for PdSi $\mathrm{FCC}$ alloy at the rate $10 \mathrm{~K} / \mathrm{ps}$.

Fig. 5, Fig. 6 highlight the structural differences between various Pd-Si alloys at melting (liquidus) and room temperature ascertained from $g(r)$ values in the liquid state and glassy state, respectively. The 
change in peak height and position reveals the structural differences within alloys at their melting temperature. Now, the shifting of peaks with temperature in pair correlation functions depends on the chemical association in Pd-Si alloys. The first peak intensity increases with its position shifting to the right, with increasing palladium content in the Pd-Si alloys. Overall, this is due to enhanced neighbourhood coordination with larger bond lengths. The former is attributable to greater metallic characteristics from $\mathrm{Pd}$, and the latter due to the directionality of the covalent bonds in Si [37].
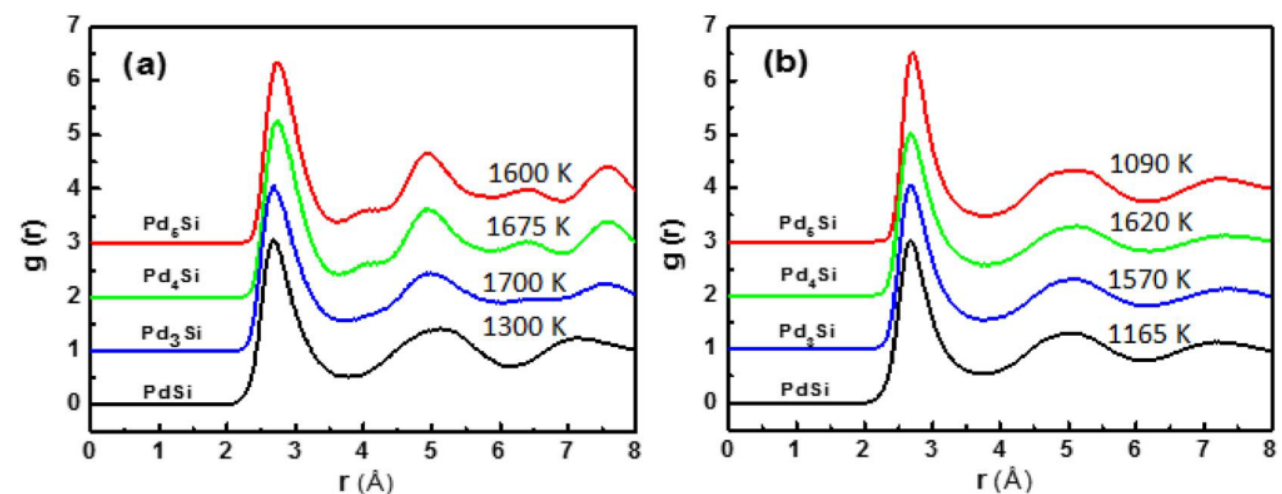

Fig. 5. Pair correlation function $\mathrm{g}(\mathrm{r})$ refers to the liquid state of (a) for Pd-Si $\mathrm{F}_{\mathrm{FCC}}$ alloys and (b) for Pd-Si $\mathrm{I}_{\mathrm{ICSD}}$ alloys at the melting temperature. Note that some crystalline characteristic remains in fcc alloys of high Pd contents (e.g. minor hillock at about $4 \AA$ and $6.5 \AA$ ), $\mathrm{Pd}_{4} \mathrm{Si}$ and $\mathrm{Pd}_{5} \mathrm{Si}$ at the rate of $10 \mathrm{~K} / \mathrm{ps}$.
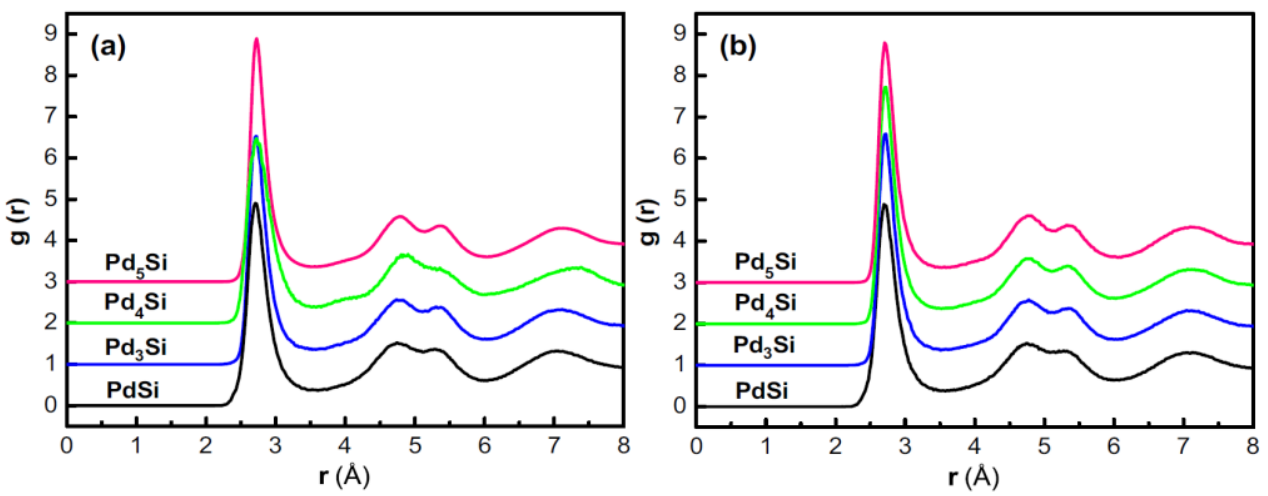

Fig. 6. Pair correlation function $g(r)$ refers to the glassy state of (a) for Pd-Si $\mathrm{F}_{\mathrm{FCC}}$ alloys and (b) for Pd-Si $\mathrm{I}_{\mathrm{ICSD}}$ alloys at $300 \mathrm{~K}$, at a cooling rate of $10 \mathrm{~K} / \mathrm{ps}$.
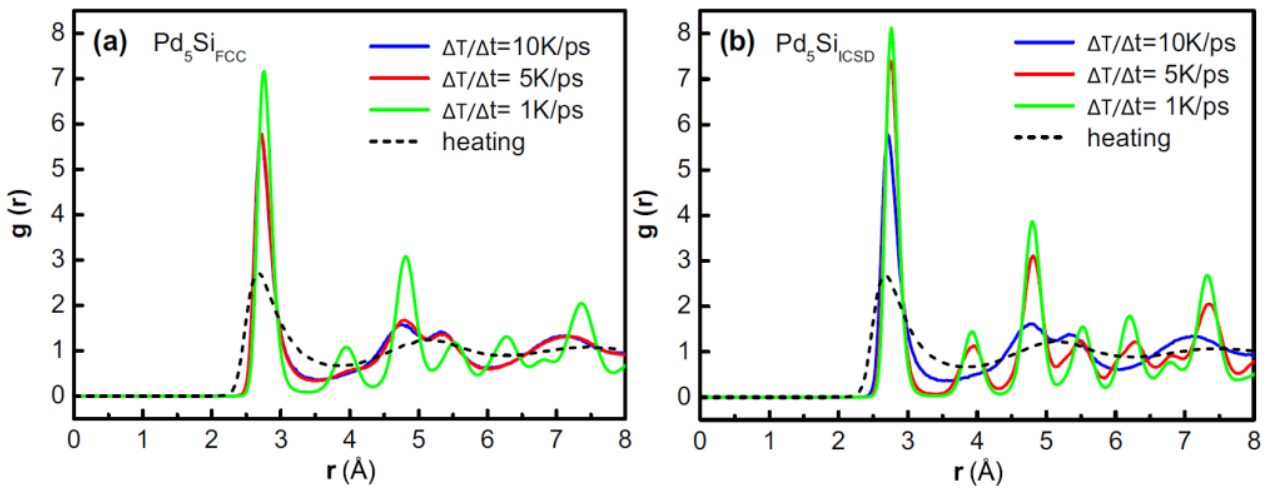

Fig. 7. Pair correlation function of (a) for $\mathrm{Pd}_{5} \mathrm{Si}_{\mathrm{FCC}}$ (b) for $\mathrm{Pd}_{5} \mathrm{Si}_{\mathrm{ICSD}}$ alloys heated (melting) at $2000 \mathrm{~K}$ and cooled to room temperature at different rates.

The structural features of Pd-Si alloys were examined in the amorphous and crystal states by extracting the pair correlation functions (PCF) during the cooling process, at three different quenching rates (Fig. 7). The splitting of the second peak of the PCF is a well-known feature of amorphous phase formation [38]. During the cooling to $300 \mathrm{~K}$ at the fast quenching rate $(5$ and $10 \mathrm{~K} / \mathrm{ps})$, the second PCF peak splits into two sub-peaks; thereby indicating the formation of a metallic glass. Conversely, as seen in Fig. 7(a), after cooling the system at $1 \mathrm{~K} / \mathrm{ps}$, the $\mathrm{Pd}_{5} \mathrm{Si}_{\mathrm{Fcc}}$ alloy crystallises and demonstrates a series of well-defined peaks in contrast to the PCF of the liquid structure at $2000 \mathrm{~K}$. On the other hand, the red curve in Fig. $7(\mathrm{~b})$ 
indicates that crystallisation already occurred when the $\mathrm{Pd}_{5} \mathrm{Si}_{1}$ CSD alloy is cooled down at an intermediate rate of $5 \mathrm{~K} / \mathrm{ps}$, demonstrating many well-defined peaks. Fig. 8 compares the representative snapshots of glass and crystalline phases.
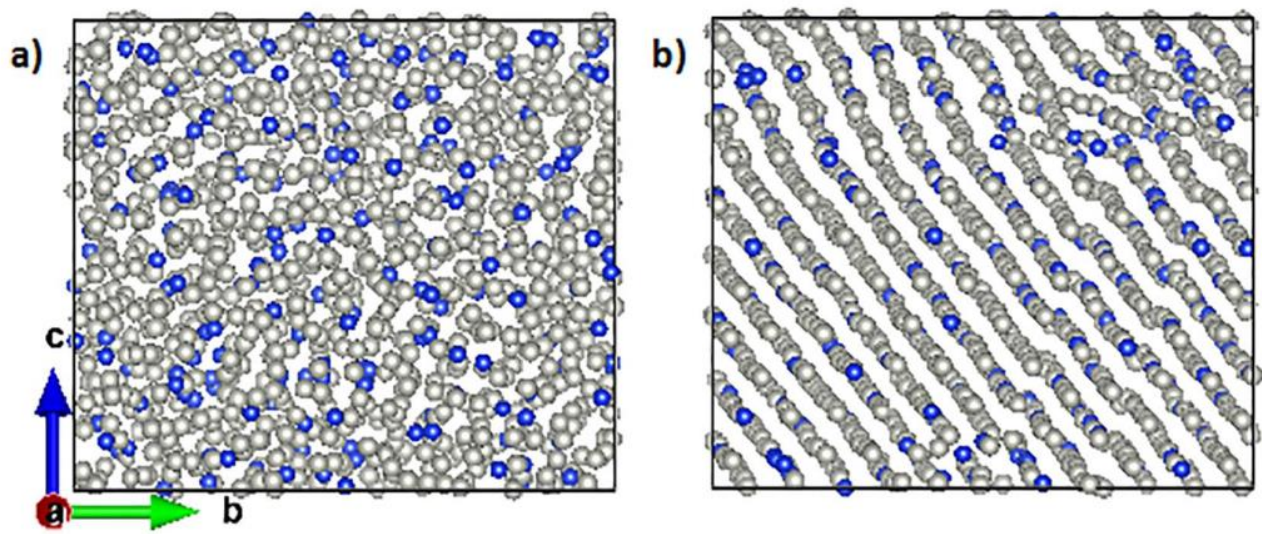

Fig. 8. Snapshot of atomic configurations for the $\mathrm{Pd}_{5} \mathrm{Si}$ (ICSD) Alloy at $300 \mathrm{~K}$; (a) the glass structure at $10 \mathrm{~K} / \mathrm{ps}$, and (b) crystalline structure at $5 \mathrm{~K} / \mathrm{ps}$.


Fig. 9. $\mathrm{g}_{\min } / \mathrm{g}_{\max }$ (Wendt-Abraham parameter) values as a function of temperature for $\mathrm{PdSi} \mathrm{i}_{\mathrm{FCC}}$ (a), $\mathrm{Pd}_{3} \mathrm{Si}_{\mathrm{FCC}}$ (b), $\mathrm{PdSi} \mathrm{i}_{\mathrm{ICSD}}$ (c) and $\mathrm{Pd} \mathrm{S}_{3} \mathrm{Si}_{\mathrm{ICSD}}$ (d) for different cooling rates (10, 5 and $1 \mathrm{~K} / \mathrm{ps}$ ).

\subsection{Glass transition temperature $\left(T_{g}\right)$}

We obtained the glass transition temperature by following the well-known "Wendt-Abraham parameter" $R$ [39], defined as $R=g_{\min } / g_{\max }$, where $g_{\max }$ and $g_{\min }$ are the magnitudes of the first maximum and next minimum in the pair distribution function (Fig. 3, Fig. 5, Fig. 6, Fig. 7), respectively. Fig. 9 [(a)-(d)] give the Wendt-Abraham parameters as a function of temperature, for the Pd-Si alloys during quenching at three different rates. Again, the influence of the cooling rate on the solidification process can be seen clearly. In Fig. 9, glass and crystallisation temperatures were obtained by Wendt-Abraham parameter from intercept method for Pd-Si alloys, with a slight change in slope attributed to the glass transition $\left(\mathrm{T}_{\mathrm{g}}\right)$, and steep change in R owing to crystallisation $\left(T_{x}\right)$. These results are presented in Table 2. 
Table 2

Glass transition $\left(\mathrm{T}_{\mathrm{g}}\right.$ ) or crystallisation temperatures $\left(\mathrm{T}_{\mathrm{x}}\right)$ for Pd, $\mathrm{Si}$ and Pd-Si alloys at three different cooling rates.

\begin{tabular}{|c|c|c|c|c|c|c|c|}
\hline \multirow[t]{2}{*}{ Composition } & \multicolumn{3}{|c|}{ Transition temperature $(\mathrm{K})$} & \multirow[t]{2}{*}{ Melting Temp. } & \multirow[t]{2}{*}{ Reduced $\mathrm{T}_{\mathrm{g}}\left(\mathrm{T}_{\mathrm{g}} / \mathrm{T}_{\mathrm{m}}\right)$ for $10 \mathrm{~K} / \mathrm{ps}$} & \multirow{2}{*}{$\begin{array}{l}\text { Theo. } \\
\mathrm{T}_{\mathrm{g}}\end{array}$} & \multirow{2}{*}{$\begin{array}{l}\text { Exp. } \\
\mathrm{T}_{g}\end{array}$} \\
\hline & $10 \mathrm{~K} / \mathrm{ps}$ & $5 \mathrm{~K} / \mathrm{ps}$ & $1 \mathrm{~K} / \mathrm{ps}$ & & & & \\
\hline $\mathrm{Si}_{\mathrm{FCC}}$ & $815 \pm 10$ & $810 \pm 10$ & $800 \pm 10$ & 1680 & 0.485 & & \\
\hline $\mathrm{PdSi}_{\mathrm{FCC}}$ & $645 \pm 10$ & $635 \pm 10$ & $\begin{array}{l}\text { Crystal } \\
\left(\mathrm{T}_{\mathrm{x}}=650 \mathrm{~K}\right)\end{array}$ & 1300 & 0.496 & & \\
\hline PdSi $i_{\text {ICSD }}$ & $615 \pm 5$ & $610 \pm 5$ & $\begin{array}{l}\text { Crystal } \\
\left(T_{x}=650 \mathrm{~K}\right)\end{array}$ & 1165 & 0.528 & & \\
\hline $\mathrm{Pd}_{3} \mathrm{Si}_{\mathrm{FCC}}$ & $720 \pm 10$ & $710 \pm 10$ & Crystal $\left(\mathrm{T}_{\mathrm{x}}=750 \mathrm{~K}\right)$ & 1700 & 0.424 & & \\
\hline $\mathrm{Pd}_{3} \mathrm{Si}_{\mathrm{ICSD}}$ & $710 \pm 5$ & $\begin{array}{l}\text { Crystal } \\
\left(T_{x}=650 \mathrm{~K}\right)\end{array}$ & $\begin{array}{l}\text { Crystal } \\
\left(\mathrm{T}_{\mathrm{x}}=850 \mathrm{~K}\right)\end{array}$ & 1570 & 0.452 & & \\
\hline $\mathrm{Pd}_{4} \mathrm{Si}_{\mathrm{FCC}}$ & $775 \pm 10$ & $\begin{array}{l}\text { Crystal } \\
\mathrm{T}_{\mathrm{x}}=750 \mathrm{~K}\end{array}$ & Crystal $\left(\mathrm{T}_{\mathrm{x}}=1050 \mathrm{~K}\right)$ & 1675 & 0.463 & & \\
\hline $\mathrm{Pd}_{4} \mathrm{Si}_{\text {ICSD }}$ & $750 \pm 5$ & $745 \pm 5$ & Crystal-glass $\left(\mathrm{T}_{\mathrm{x}}=750 \mathrm{~K}\right)$ & 1620 & 0.463 & $657^{\mathrm{a}}, 943^{\mathrm{c}}$ & $655^{\mathrm{b}}$ \\
\hline $\mathrm{Pd}_{5} \mathrm{Si}_{\mathrm{FCC}}$ & $750 \pm 10$ & $740 \pm 10$ & $\begin{array}{l}\text { Crystal } \\
\left(T_{x}=900 \mathrm{~K}\right)\end{array}$ & 1600 & 0.469 & & \\
\hline $\mathrm{Pd}_{5} \mathrm{Si}_{\mathrm{ICSD}}$ & $730 \pm 5$ & $\begin{array}{l}\text { Crystal-glass } \\
\left(T_{x}=650 \mathrm{~K}\right)\end{array}$ & $\begin{array}{l}\text { Crystal } \\
\left(\mathrm{T}_{\mathrm{x}}=850 \mathrm{~K}\right)\end{array}$ & 1090 & 0.670 & $643^{\mathrm{a}}$ & \\
\hline $\mathrm{Pd}_{\mathrm{FCC}}$ & $765 \pm 10$ & $\begin{array}{l}\text { Crystal-glass } \\
\mathrm{T}_{\mathrm{x}}=750 \mathrm{~K}\end{array}$ & $\begin{array}{l}\text { Crystal-glass } \\
\mathrm{T}_{\mathrm{x}}=950 \mathrm{~K}\end{array}$ & 1810 & 0.423 & $799^{d}$ & \\
\hline
\end{tabular}

\footnotetext{
a Thermodynamic Model (Calphad) Ref. [40].

${ }^{\mathrm{b}}$ Experimental result Ref. [41].

c MD (EAM) Ref. [42].

${ }^{\mathrm{d}} \mathrm{MD}$ (Q-SC) Ref. [9].
}

The evolution of the slope in the cooling curves (Fig. 9) is dependent upon the cooling rates i.e. when the cooling rate is high, crystallisation is avoided, leading to glass formation whereas when the cooling rates are low $(1 \mathrm{k} / \mathrm{ps})$, crystallisation occurs. Such dependency on cooling rate is shown with the snapshots of atomic configurations for the $\mathrm{Pd}_{3} \mathrm{Si}$ (ICSD) alloy in Fig. 10. The glass transition temperature increases linearly with the $\mathrm{Pd}$ content, with a maximum at $80 \% \mathrm{Pd}$ (Table 2). For the same alloy, a larger cooling rate leads to a lower $\mathrm{T}_{\mathrm{g}}$ for adequate structural relaxation and evolution of medium range order in a glassy phase.

(a) Solid at room temperature

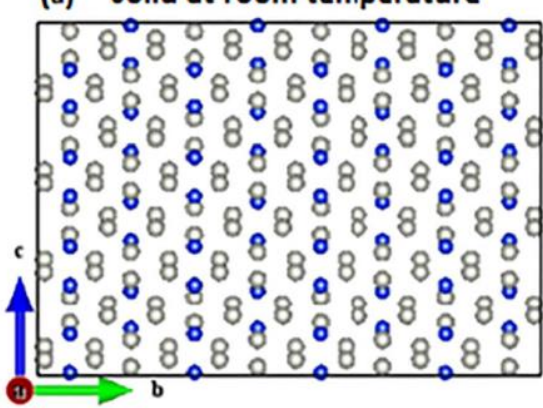

(c) Glass at room temp. (10K/ps)

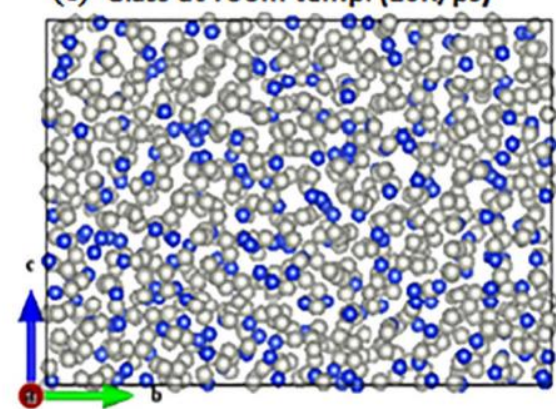

(b) Liquid at $2000 \mathrm{~K}$

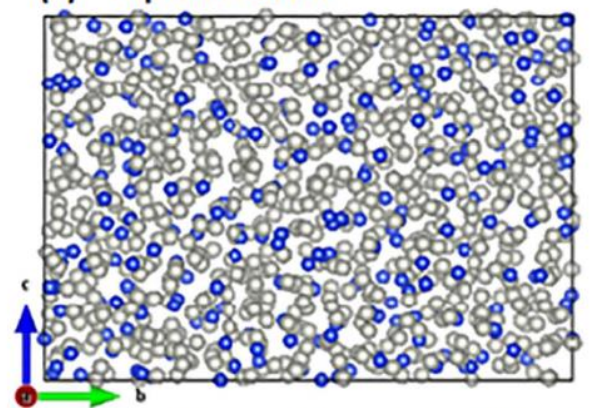

(d) Crystallisation at room temp.(5K/ps)

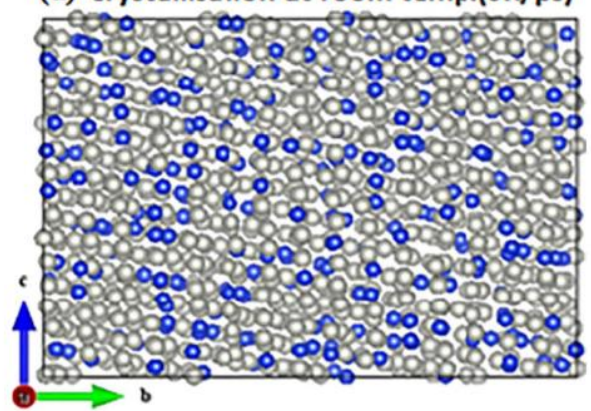

Fig. 10. Snapshot of atomic configurations for the $\mathrm{Pd}_{3} \mathrm{Si}$ (ICSD) Alloy; (a) starting crystalline structure, (b) liquid structure at $2000 \mathrm{~K}$, (c) glass due to quenching the liquid at $10 \mathrm{~K} / \mathrm{ps}$, and (d) crystalline structure due to quenching from liquid at $5 \mathrm{~K} / \mathrm{ps}$.

\subsection{Crystallisation temperature}

The crystallisation temperature $\left(T_{x}\right)$ of an amorphous alloy is a well-known indicator of glass forming ability (GFA) [40]. In binary metallic glasses, there is usually a very small temperature difference between 
$T_{x}$ and glass transition temperature $\left(T_{g}\right)$. This temperature interval, the so-called supercooled liquid region $\Delta T_{x}=\left(T_{x}-T_{g}\right)$, is determined upon devitrification and constitutes a quantitative measure of the stability of the supercooled liquid. A large $\Delta T_{x}$ value indicates that the supercooled liquid can exist in a wide temperature range without crystallisation, thus leading to a larger GFA for the alloy [43]. The crystallisation resistance is determined by crystallisation mechanism involving crystal nucleation and growth. As crystallisation of the prior amorphous phase is diffusion-controlled wherein it is assumed that $\mathrm{T}_{\mathrm{x}}$ is determined by an effective diffusion length $x=(D t)^{-1 / 2}$ (where $D$ is the diffusion coefficient and $t$ is time) [44]. The crystallisation temperature rises with increasing Pd content in Pd-Si alloys. An alternative indicator for glass forming ability is the reduced transition temperature, $T_{g} / T_{m}$, with a higher value indicating better glass forming ability. The resultant transition temperatures are summarised in Table 2.

\subsection{Structural relaxation in metallic glasses}

The metallic glasses evolves as a metastable phase from the liquid state through melt quenching, when some medium range order (MRD) is developed through structural relaxation below the glass transition $\left(T_{g}\right)$ temperature $[44,45]$. It is worth pointing out that supercooled liquid can be obtained at extremely high quenching rate that may not permit structural relaxation. When an isothermal annealing below $T_{\mathrm{g}}$ is applied, the supercooled liquid phase may experience further structural relaxation for lowered system energy [46]. Crystallisation of the glass happens when prolonged annealing is applied, through equilibration in the material system $[40,43,44,46]$.

In order to examine the crystallisation process, variations of the cell volume, internal energy, and atomic arrangement are observed in the MD simulations, as illustrated in Fig. 11. When the internal energy of the amorphous system reaches its lowest level, the atoms get closer to the equilibrium positions, resulting in the disordered state becoming a well-ordered crystalline state. As a result of these atomic structural changes, the system volume reduces [47].

Fig. 11(a) illustrates the variation of the cell volume and internal energy occurring during the annealing process at $500 \mathrm{~K}$. It can be seen from the plot that there are sharp drops (from position $t_{1}$ to $t_{2}$ ) in the internal energy as well as cell volume, owing to enhanced bonding via crystallisation. It is interesting to note the change in the slopes of the curves (Fig. 11) corresponding to different crystallisation stages during annealing. According to Fig. 11, the stages of crystallisation can be defined from the start of annealing ( $t_{1}$, first stage), time $t_{1}$ to time $t_{2}$ (second stage) and from time $t_{2}$ to the end of simulation (the third/final stage). The first stage experiences structural relaxation and possibly nucleation with slight reduction in the internal energy. The second stage is when crystallisation evolves quickly via growth, and the final stage only experiences coarsening or reduction of disorder or defects in the crystalline phases.


Fig. 11. Variation of cell volume (a) and energy (b) during annealing at $500 \mathrm{~K}$. 
The influence of the annealing temperature on the crystallisation process was also examined in the MD simulations. Fig. 12 illustrates the variations of the internal energy at different annealing temperatures from the room temperature $(300 \mathrm{~K})$ glass. It can be observed that the internal energy declines very slowly at the annealing temperature of $500 \mathrm{~K}$. Furthermore, no sharp energy change is observed and the total change of energy is minimal. Therefore, it is clear that there is only some structural relaxation without crystallisation occurring at the annealing temperature of $500 \mathrm{~K}$. On the other hand, for the simulation cases with the annealing temperature of $600 \mathrm{~K}$ and $700 \mathrm{~K}$, the internal energy curves follow a similar trend to that of the $500 \mathrm{~K}$ case of pure Pd (Fig. 11(b)). Therefore, it can be concluded (Fig. 12) that the higher the annealing temperature, the faster is the crystallisation process, which is consistent with experimental observations [48].

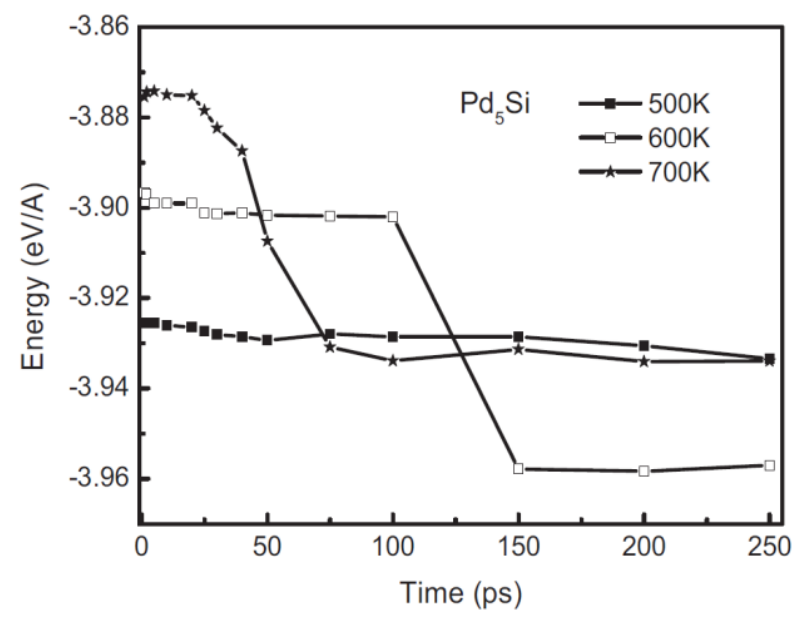

Fig. 12. Variation of energy during annealing at different temperatures from $300 \mathrm{~K}$ glas of $\mathrm{Pd}_{5} \mathrm{Si}_{\mathrm{ICSD}}$.

The structural progress during annealing at different temperatures and the presence of the three stages over crystallisation is further confirmed with the PCF evidence [47]. Fig. 13 demonstrates the PCFs after different annealing periods during crystallisation at $500 \mathrm{~K}$ and $700 \mathrm{~K}$ for the pure $\mathrm{Pd}$ and $\mathrm{Pd}_{5} \mathrm{Si}_{\text {ICSD }}$ alloy. It can be seen that the annealing process starts from the amorphous phase as the PCF demonstrates the fingerprint splitting of the second peak for a glassy phase. The $15 \mathrm{ps}(\mathrm{Pd})$ and $20 \mathrm{ps}\left(\mathrm{Pd}_{5} \mathrm{Si} \mathrm{i}_{1 \mathrm{CSD}}\right)$ correspond to the end of the first stage of crystallisation, when the split of the second peak becomes less obvious owing to the nucleation of crystal phase. The annealing time of $40 \mathrm{ps}(\mathrm{Pd})$ and $75 \mathrm{ps}\left(\mathrm{Pd}_{5} \mathrm{Si} i_{\text {ICSD }}\right)$ correspond to the end of the second stage of crystallisation, with the PCFs exhibiting crystalline characteristics with the appearance of many peaks. During the third stage of crystallisation, the crystalline peaks in the PCFs at $50 \mathrm{ps}(\mathrm{Pd}), 100,150$ and $250 \mathrm{ps}$ ( $\mathrm{Pd}_{5} \mathrm{Si}_{\text {ICSD }}$ ) become even sharper, as the crystalline phase becomes more perfect through reduction of defects and enhanced crystallinity, as shown in Fig. 14. 

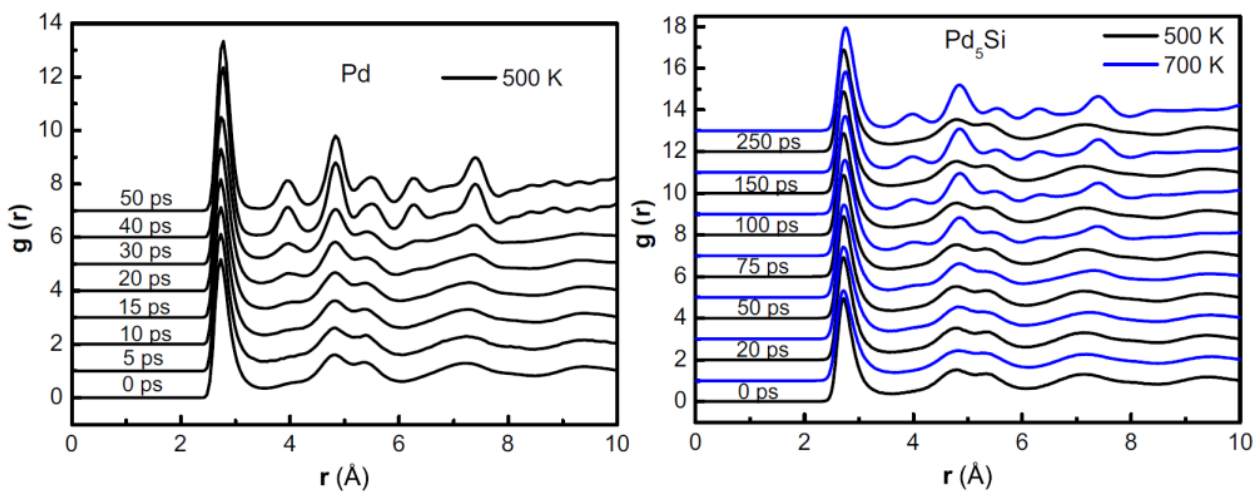

Fig. 13. Pair correlation function for the evolution of crystallisation by structural relaxation for Pd metal at $500 \mathrm{~K}$ (a) and $\mathrm{Pd}_{5} \mathrm{Si}_{\mathrm{ICSD}}$ (b) from $300 \mathrm{~K}$ glass.

\subsection{Compositional effect}

The concentration effects on the glass transition and crystallisation were studied by plotting the unit cell volume of $\mathrm{Pd}-\mathrm{Si}$ alloys as a function of temperature (Fig. 15) with the corresponding PCF for quenched alloys shown in Fig. 16. Together these suggest that the liquid structures associated with different starting solid have some impact on the structural evolution during cooling. For the FCC solid system at the range of cooling rates of interest, only glass transition occurs in the alloys. The $\mathrm{Pd}_{3} \mathrm{Si}$ and $\mathrm{Pd}_{5} \mathrm{Si}_{\text {ICSD }}$ alloys experience crystallisation instead, as demonstrated in the snapshots of structural configurations (Fig. 17) at room temperature. 


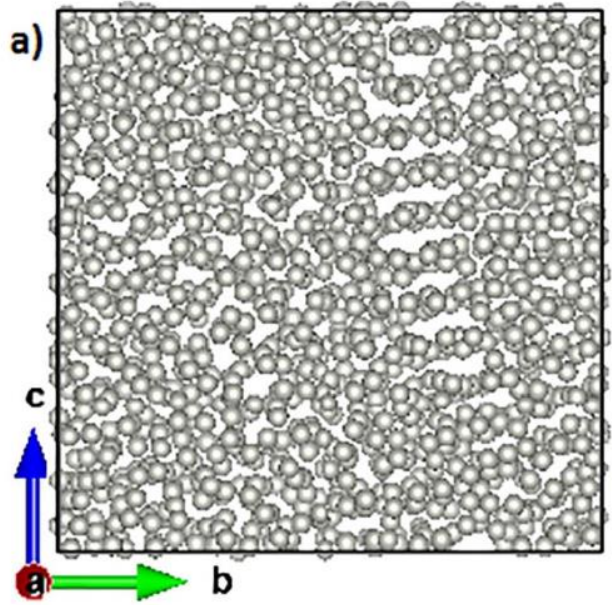

b)



Fig. 14. Snapshot of atomic configurations for the evolution of crystallisation by structural relaxation for Pd metal at $500 \mathrm{~K}$ (a) 0 ps and (b) 50 ps.
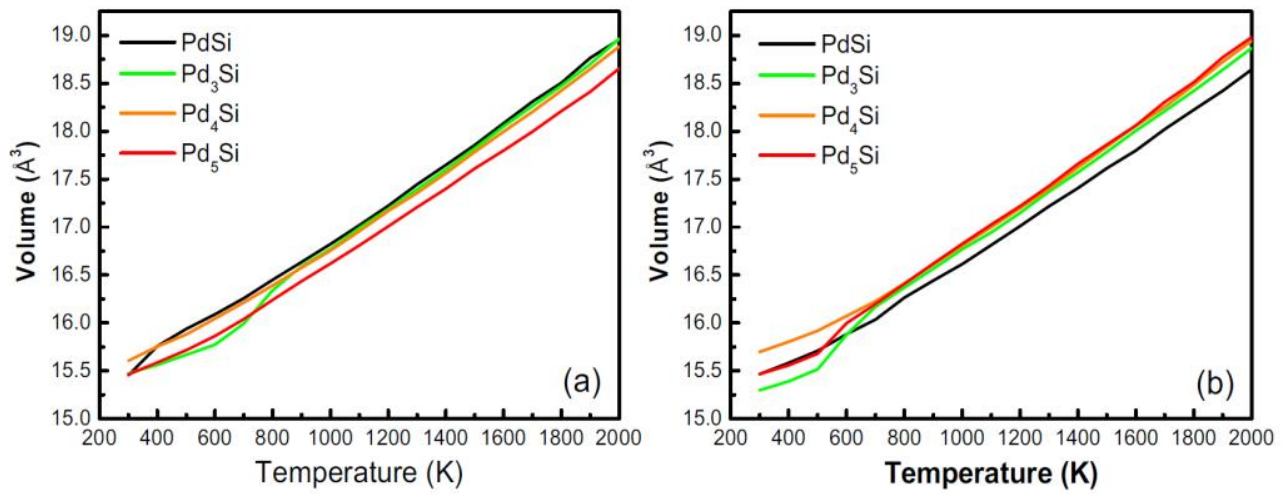

Fig. 15. Cell Volume of Pd-Si $\mathrm{i}_{\mathrm{FCC}}$ (a) and Pd-Si $\mathrm{I}_{\mathrm{ICSD}}$ alloys as a function of temperature during the cooling process at the rate of $5 \mathrm{~K} / \mathrm{ps}$.


Fig. 16. Pair correlation function at room temperature of (a) for $\mathrm{Pd}-\mathrm{Si}_{\mathrm{FCC}}$ and (b) for $\mathrm{Pd}-\mathrm{Si}_{\mathrm{ICSD}}$ alloys during cooling with a rate of $5 \mathrm{~K} / \mathrm{ps}$.

\subsection{Criterion of glass forming ability}

Glass formation is enabled through the avoidance of nucleation and subsequent growth of critical nuclei. In the glass forming alloys, the former is dictated by a transient nucleation process, with the incubation time for the formation of critical sized nuclei being inversely proportional to the diffusion coefficient in the undercooled melt [50]. GFA can be characterised by several parameters. The reduced glass transition temperature $\left(T_{r g}=T_{g} / T_{m}\right)$ is an extensively used indicator of GFA of alloys [51], which is suggestive of undercooling needed to reach the critical temperature for glass formation, $T_{g}$, below which crystallisation will be avoided due to inadequate diffusion. The higher the $T_{r g}$, the easier for glass formation owing to the narrow gap between $T_{m}$ and $T_{g}$. Tables 2 summarises the available experimental data and calculated results of $T_{g}, T_{m}$, and $T_{r g}$ versus $\mathrm{Pd}$ concentration for Pd-Si alloys. Shao [3] proposed that $T_{g}$ is related to the melting temperature rather differently between pure metals and glass forming alloys $\left(T_{g}=0.25 T_{m}\right.$ in 
pure metals, and (0.5-0.8) $T_{m}$ in glass forming alloys). From the comparison of $T_{r g}$ values from MD (Table 2 ), it is apparent that the MD calculated $\mathrm{T}_{\mathrm{rg}}$ values are slightly lower than $0.5 \mathrm{~T}_{\mathrm{m}}$ except for that of the $\mathrm{Pd}_{5} \mathrm{Si}_{1}$ CSD. Such discrepancy can be attributed to the fact that congruous melting points are used in the current simulation, while there is uncertainty in the melting point data assumed in the experimental work due to the existence of solidus and liquidus.

As we can observe in Table 2, the alloys with the $\mathrm{Pd}_{5} \mathrm{Si}$ and $\mathrm{PdSi}$ compositions showed higher glass forming ability. These compositions coincide with the two major eutectic valleys in the Pd-Si phase diagram, which involve phases of narrow solubility ranges. Such eutectic valleys are known to be beneficial for glass formation, owing firstly to the energetic constraint of the competing solid phases under limited diffusion conditions and secondly the enhancement of the reduced glass transition temperature. There is also evidence in the effect of structural inheritance of solid in the liquid phase under the same heating condition used in the simulation (see Fig. 5), leading to changes in simulated temperatures.

\subsection{Diffusivity in metallic glasses}

Diffusion coefficients of Pd-Si alloys were estimated from the Einstein relation and calculated mean square displacement (MSD) measured by summation over squares of the particle displacement, with results being plotted in Fig. 18, Fig. 19. Upon heating, the diffusion coefficient in $\mathrm{Pd}_{3} \mathrm{Si}$ alloy remains constant up to melting at $1600 \mathrm{~K}$ (Fig. 18a) and $1500 \mathrm{~K}$ (Fig. 18b), before rising sharply. The significant leap in diffusion constant for $\mathrm{Pd}$ in $\mathrm{Pd}_{3} \mathrm{Si}$ alloys can be attributed to the phase transition from the solid to the liquid state, wherein weaker atomic association due to higher thermal excitation leads to remarkably higher diffusion coefficient. Upon cooling, it decreases almost linearly against temperature and to some extent almost independent of the cooling rate. As anticipated, diffusion becomes very weak below the crystallisation point owing to the stronger atomic association in the amorphous structure. The diffusion

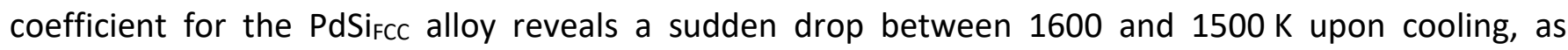
illustrated in Fig. 19 (a), before recovering (at $1400 \mathrm{~K}$ ) the trend expected from the higher temperature data. Conversely, it can be observed from the Pd-SiICSD alloys (Fig. 19) that the Pd and Si atoms do not experience the radical shaking in that seen for $\mathrm{Pd}-\mathrm{Si}_{\mathrm{FCC}}$, indicating the lack of sudden change in structure during cooling. 
(a) PdSircsD

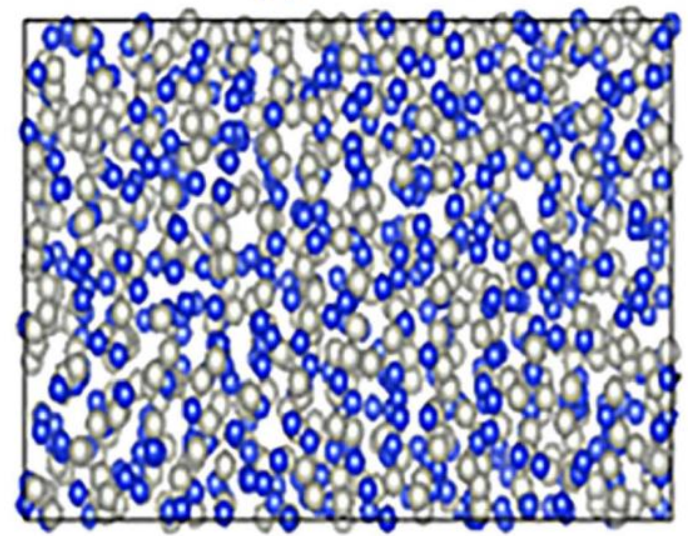

(c) $\mathrm{Pd}_{4} \mathrm{SiICSD}$

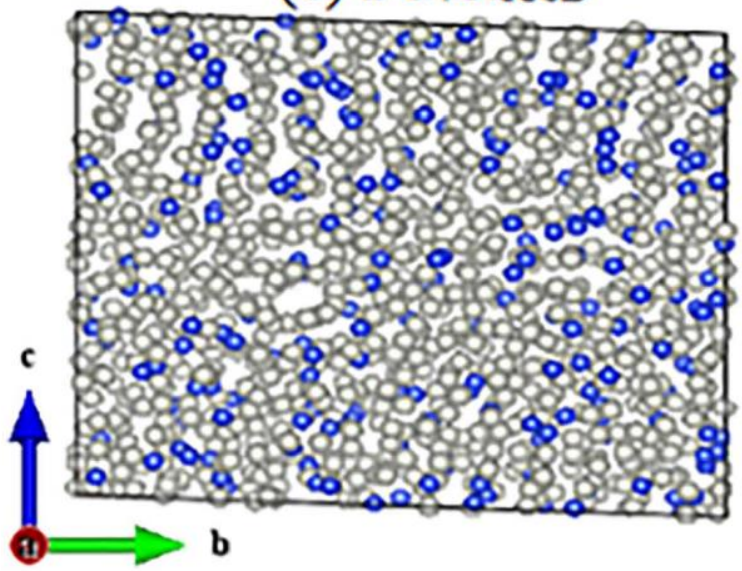

(b) $\mathrm{Pd}_{3} \mathrm{SiICsD}$

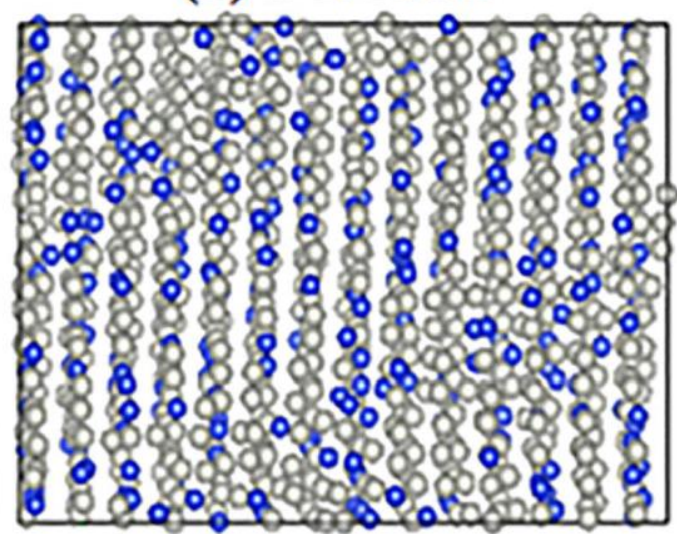

(d) $\mathrm{Pd}_{5} \mathrm{Si} \mathrm{SCSD}$

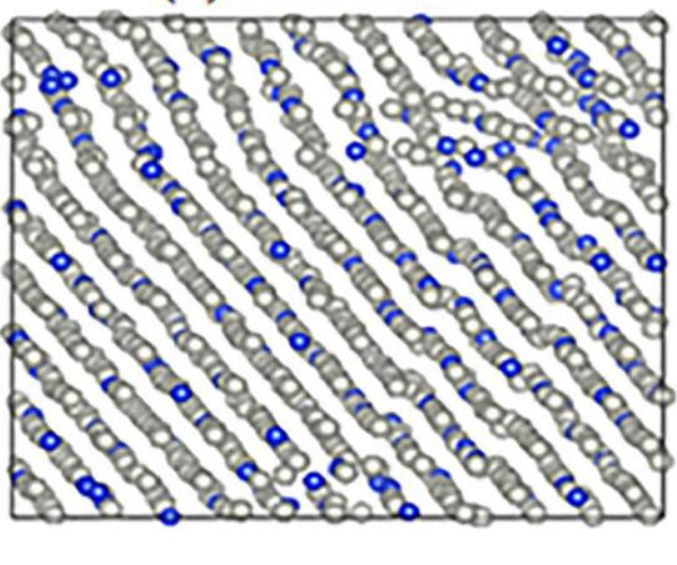

Fig. 17. Snapshots of atomic structure of glass (a \& c) and crystalline (b \& d) state at $300 \mathrm{~K}$ for real Pd-Si system at the cooling rate of $5 \mathrm{~K} / \mathrm{ps}$.


Fig. 18. Diffusion coefficient vs temperature upon heating and cooling for $\mathrm{Pd}$ in $\mathrm{Pd}_{3} \mathrm{Si}_{\mathrm{FCC}}$ (a) and $\mathrm{Pd}_{3} \mathrm{Si}_{\mathrm{ICSD}}$ (b) alloy, at $10 \mathrm{~K} / \mathrm{ps}$ and $5 \mathrm{~K} / \mathrm{ps}$ cooling rates. 

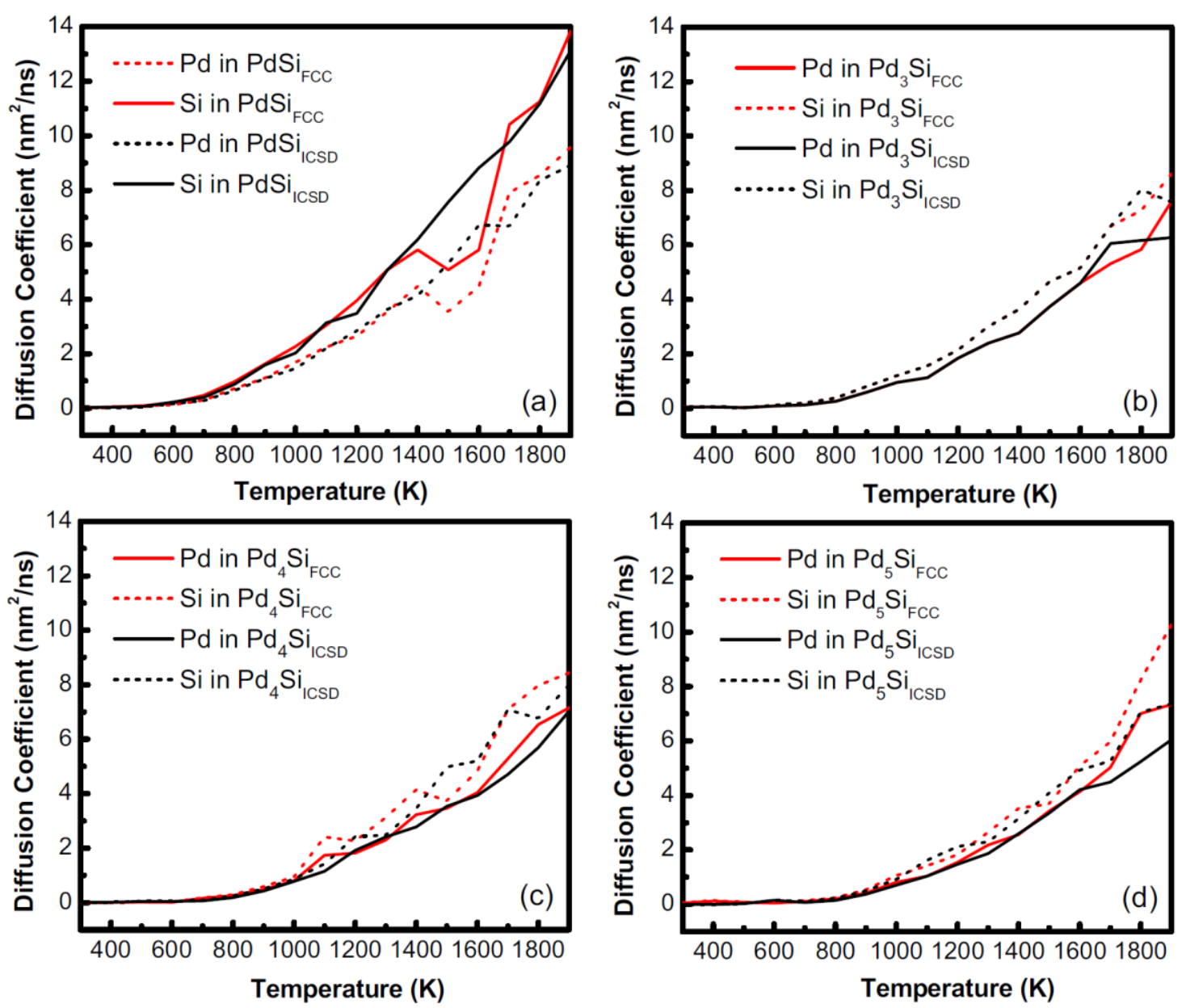

Fig. 19. Diffusion coefficient vs temperature for $\mathrm{PdSi}(\mathrm{a}), \mathrm{Pd}_{3} \mathrm{Si}$ (b) $\mathrm{Pd}_{4} \mathrm{Si}$ (c) and $\mathrm{Pd}_{5} \mathrm{Si}$ (d) alloys upon cooling (10 K/ps) from the liquid state.

\subsection{Cluster analysis of metallic glasses}

A cluster is composed of a set of atoms within a certain length, or the cut-off distance. Two atoms within a cluster are considered neighbours when there are no other atoms between them. It is vital to study the cluster evolution ranging from several atoms to bulk crystals as the number of atoms rises. Glass is typically considered as a relaxed "frozen liquid". In other words, during fast cooling, the numerous clusters in liquid do not have sufficient time to form more stable crystalline phase/s. Conversely, under slow cooling, various types of clusters in liquid metal will be rearranged in a particular order to form crystalline phase/s. Therefore, it is highly useful to study the clustering process in liquids, alongside atomic rearrangement in the process of solidification. To understand the detail of atomic arrangements of metallic glasses in $\mathrm{Pd}$-Si alloys, we have analysed the clustering behaviour by calculating the number of clusters with increasing cut-off radius, as presented in Fig. 20. The figures reveal that PdSi forms the minimum number of clusters at a specified cut-off length, in contrast, $\mathrm{Pd}_{4} \mathrm{Si}$ and $\mathrm{Pd} 5 \mathrm{Si}$ have the highest numbers of clusters in undercooled liquids. One notes that the number of clusters drops upon decreasing the temperature, with corresponding enlargement of the cluster size. 

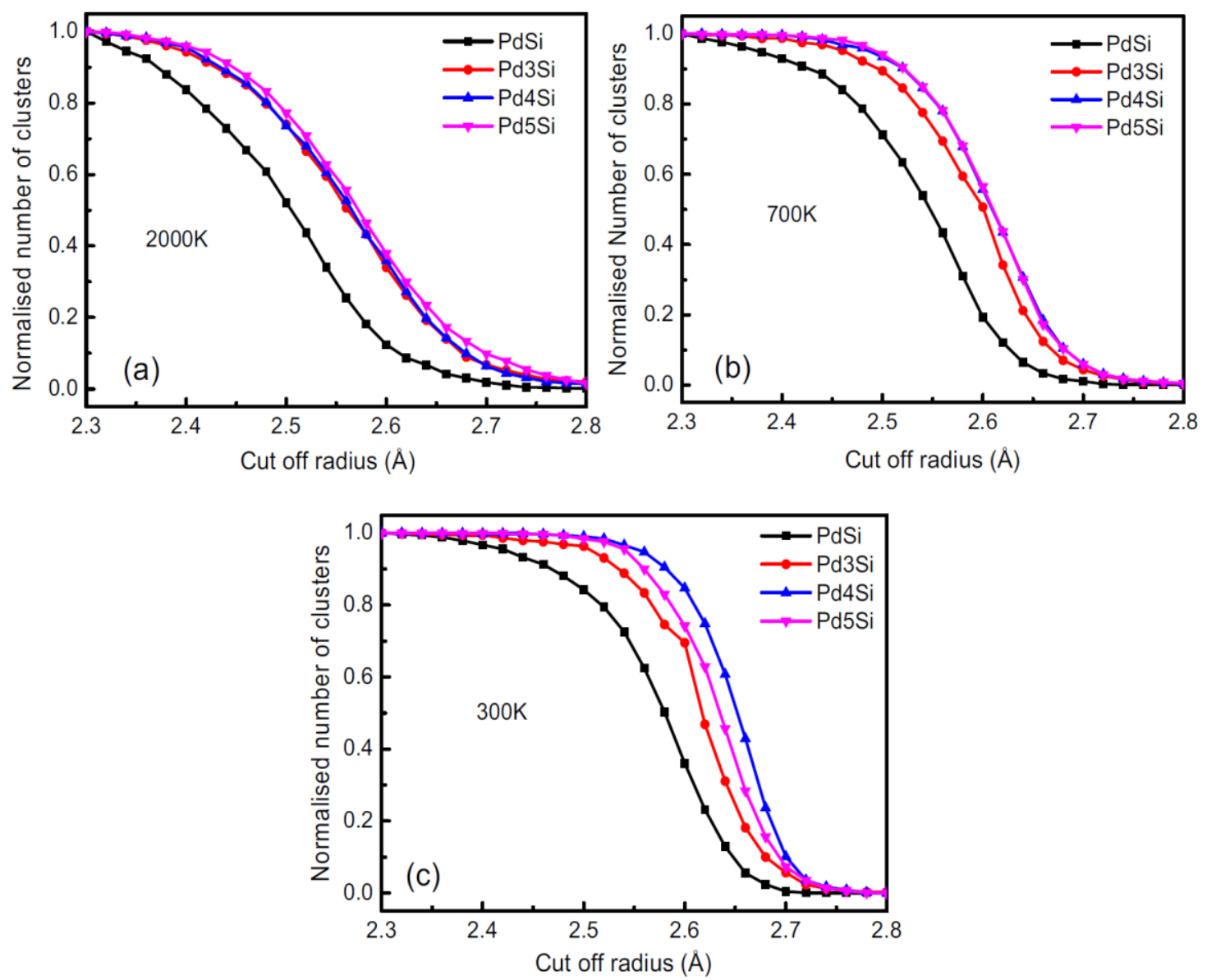

Fig. 20. Normalised number of clusters vs cutoff radius for Pd-Si $\mathrm{FCC}_{\mathrm{FC}}$ alloys at different temperatures during cooling a) $2000 \mathrm{~K}$, b) $700 \mathrm{~K}$, and c) $300 \mathrm{~K}$.

The variable cut-off values for the cluster analysis during cooling were determined based on the first peak position (left side of a peak at $85 \%$ of the peak height) in the pair correlation function (Table 3 ), alongside the number of clusters vs cut-off radius plot (Fig. 20). As can be seen clearly from cluster analysis (Table $4)$, the total number of clusters in each Pd-Si alloy increases with decreasing temperatures. As a consequence of enhanced clustering, atomic diffusion becomes more and more difficult in the undercooled liquid, which is fundamentally essential for delayed nucleation $[49,50]$. It is important to note that alloys of higher reduced glass transition temperatures are also more prone to clustering during cooling, as higher $T_{g}$ is suggestive of better thermodynamic stability of the glassy phase with respect to the supercooled liquid, thus tending to evolve medium range ordering to form the glassy phase during cooling [3]. Therefore, it can be proposed that GFA is linked to cluster evolution in Pd-Si alloys. Accordingly, Fig. 20 reveals that $\mathrm{Pd}_{4} \mathrm{Si}$ and $\mathrm{Pd}_{5} \mathrm{Si}$ alloys have greater number of large cluster sizes that can lead to improved GFA at room temperature than other Pd-Si alloys. 
Table 3

Position $(\AA)$ of the $(0.85 \times$ peak height corresponding position (left) $)$ height of first peak in PCF as function of composition and temperature for Pd-Si alloys.

\begin{tabular}{lllllll}
\hline \multirow{2}{*}{ Composition } & \multicolumn{7}{l}{ Temperature (K) } \\
\cline { 2 - 7 } & 2000 & 1500 & 1000 & 700 & 500 & 300 \\
\hline $\mathrm{PdSi}_{\mathrm{FCC}}$ & 2.521 & 2.551 & 2.587 & 2.613 & 2.631 & 2.638 \\
$\mathrm{PdSi}_{\text {ICSD }}$ & 2.522 & 2.548 & 2.589 & 2.612 & 2.629 & 2.638 \\
$\mathrm{Pd}_{3} \mathrm{Si}_{\mathrm{FCC}}$ & 2.522 & 2.551 & 2.587 & 2.620 & 2.621 & 2.638 \\
$\mathrm{Pd}_{3} \mathrm{Si}_{\text {ICSD }}$ & 2.558 & 2.577 & 2.602 & 2.613 & 2.638 & 2.657 \\
$\mathrm{Pd}_{4} \mathrm{Si}_{\mathrm{FCC}}$ & 2.559 & 2.581 & 2.626 & 2.663 & 2.678 & 2.686 \\
$\mathrm{Pd}_{4} \mathrm{Si}_{\text {ICSD }}$ & 2.551 & 2.584 & 2.613 & 2.631 & 2.649 & 2.657 \\
$\mathrm{Pd}_{5} \mathrm{Si}_{\mathrm{FCC}}$ & 2.558 & 2.587 & 2.613 & 2.675 & 2.675 & 2.685 \\
$\mathrm{Pd}_{5} \mathrm{Si}_{\text {ICSD }}$ & 2.569 & 2.584 & 2.613 & 2.641 & 2.649 & 2.657 \\
\hline
\end{tabular}

Table 4

Cluster analysis of Pd-Si alloys from above melting temperature for a variable cut-off radius.

\begin{tabular}{|c|c|c|c|c|c|c|c|}
\hline \multirow[t]{2}{*}{ Composition } & & \multicolumn{6}{|c|}{ Temperature (K) } \\
\hline & & 2000 & 1500 & 1000 & 700 & 500 & 300 \\
\hline \multirow[t]{2}{*}{$\mathrm{PdSi}_{\mathrm{FCC}}$} & NOC & 546 & 420 & 305 & 258 & 167 & 192 \\
\hline & LCS & 29 & 125 & 543 & 873 & 1135 & 1097 \\
\hline \multirow{2}{*}{$\mathrm{PdSi}_{\text {ICSD }}$} & NOC & 423 & 329 & 214 & 162 & 98 & 136 \\
\hline & LCS & 30 & 126 & 607 & 159 & 864 & 836 \\
\hline \multirow{2}{*}{$\mathrm{Pd}_{3} \mathrm{Si}_{\mathrm{FCC}}$} & NOC & 798 & 672 & 543 & 509 & 475 & 364 \\
\hline & LCS & 14 & 49 & 60 & 85 & 91 & 753 \\
\hline \multirow{2}{*}{$\mathrm{Pd}_{3} \mathrm{Si}_{\mathrm{ICSD}}$} & NOC & 440 & 361 & 360 & 315 & 229 & 127 \\
\hline & LCS & 56 & 50 & 78 & 103 & 571 & 852 \\
\hline \multirow{2}{*}{$\mathrm{Pd}_{4} \mathrm{Si}_{\mathrm{FCC}}$} & NOC & 546 & 471 & 325 & 197 & 133 & 136 \\
\hline & LCS & 24 & 69 & 441 & 769 & 1062 & 1074 \\
\hline \multirow[t]{2}{*}{$\mathrm{Pd}_{4} \mathrm{Si}_{\mathrm{ICSD}}$} & NOC & 551 & 423 & 336 & 232 & 191 & 216 \\
\hline & LCS & 21 & 47 & 257 & 819 & 916 & 878 \\
\hline \multirow[t]{2}{*}{$\mathrm{Pd}_{5} \mathrm{Si}_{\mathrm{FCC}}$} & NOC & 583 & 405 & 342 & 116 & 162 & 197 \\
\hline & LCS & 23 & 193 & 145 & 998 & 906 & 666 \\
\hline \multirow[t]{2}{*}{$\mathrm{Pd}_{5} \mathrm{Si}_{\mathrm{ICSD}}$} & NOC & 455 & 449 & 331 & 215 & 251 & 193 \\
\hline & LCS & 44 & 47 & 125 & 732 & 716 & 850 \\
\hline
\end{tabular}

NOC - No. of clusters; LCS - Largest cluster size (atoms).

In order to describe the geometric configurations of an atomic cluster for different systems, such as amorphous and liquid phases, bond angle analysis (BAA) has been developed by Auckland and Jones to differentiate between FCC, HCP and BCC coordination structures. The aim of BAA is to deliver a practical and efficient method of assigning local crystal structure. The BAA method is a three-body correlation explaining the spatial associations of three neighbouring atoms [51] and is computed from the $\mathrm{N}$ bond vectors of the central atom. BAA is calculated initially an eight-bin histogram of the $N(N-1) / 2$ bond angle cosines, $\cos \theta_{i j k}$. Here, $\theta_{i j k}$ represents the angle formed by the central atom $i$, and two of its neighbours, $j$ and $\mathrm{k}$. The determined histogram is further assessed using a set of heuristic decision rules to obtain the most likely structure type. For the BAA method, the number of neighbouring atoms used to calculate the bond angle distribution is determined adaptively by employing a cut-off radius proportional to the average distance of the six nearest neighbours.

Using the BAA method, we have calculated the relative amount of bonded structure during cooling from the melt for the Pd-Si ICSD alloys, as presented in Fig. 21. We can observe that the higher percentage within the known crystal structure is occupied by the FCC cluster at room temperature. Conversely, the development of icosahedral cluster increases slowly with decreasing temperature, which is supported by 
earlier reports from Liu et al. [51]. Figs. 21(a) and (b) also indicate that the formation tendency of bonded structures has increased; whereby the alloys systems are cooled to room temperature from the liquid structure. Furthermore, to identify the alloy which shows the best glass forming ability, we have estimated the relative amount of individual bonded atomic clusters (i.e. percentage of ICO) for the Pd-SiICSD alloys, as illustrated in Fig. 22. In general, the glass system is largely a disordered structure that has a greater tendency to form icosahedral clusters at room temperature [51].
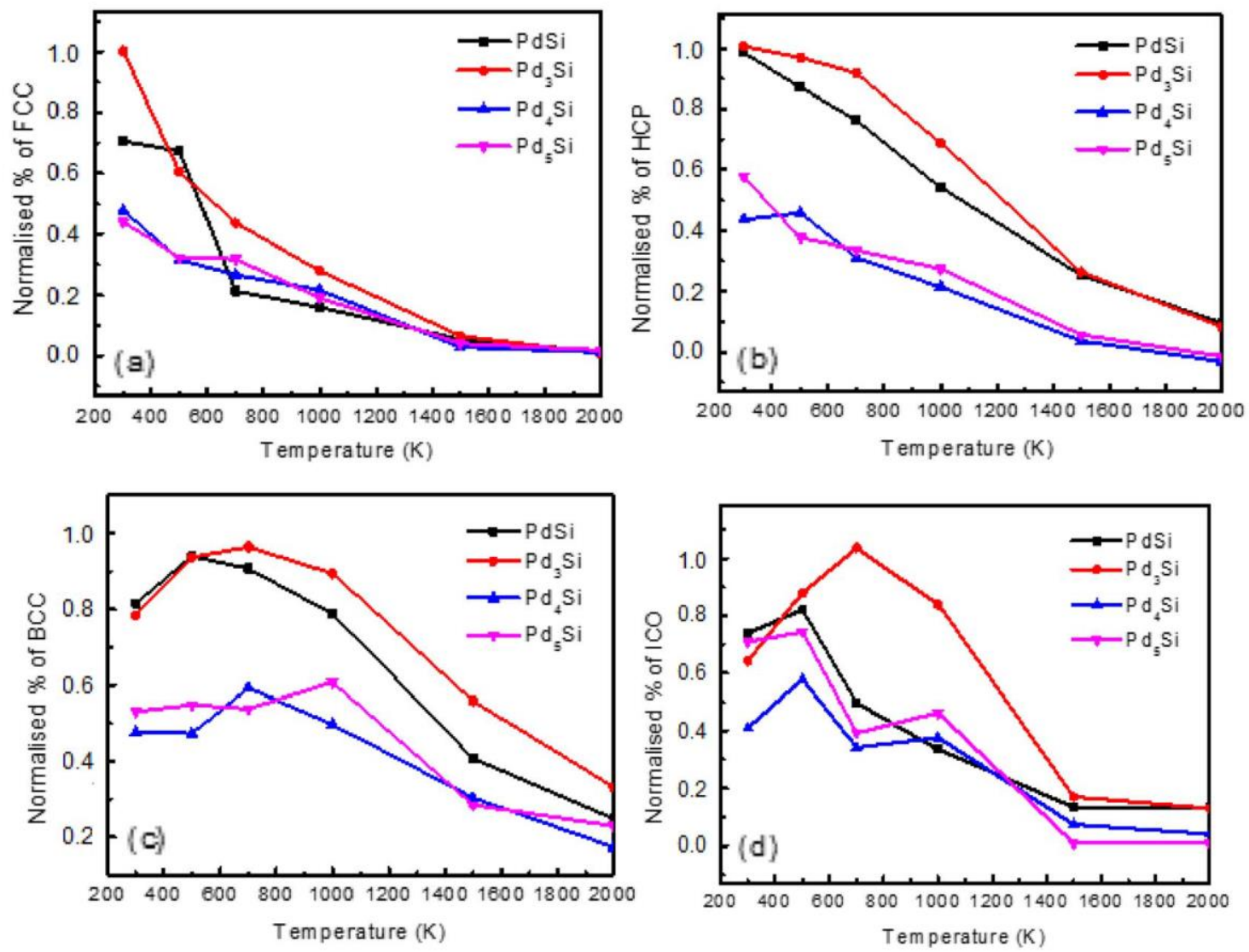

Fig. 21. The relative number of some bonded atoms (normalised) with temperatures during cooling from the melt.
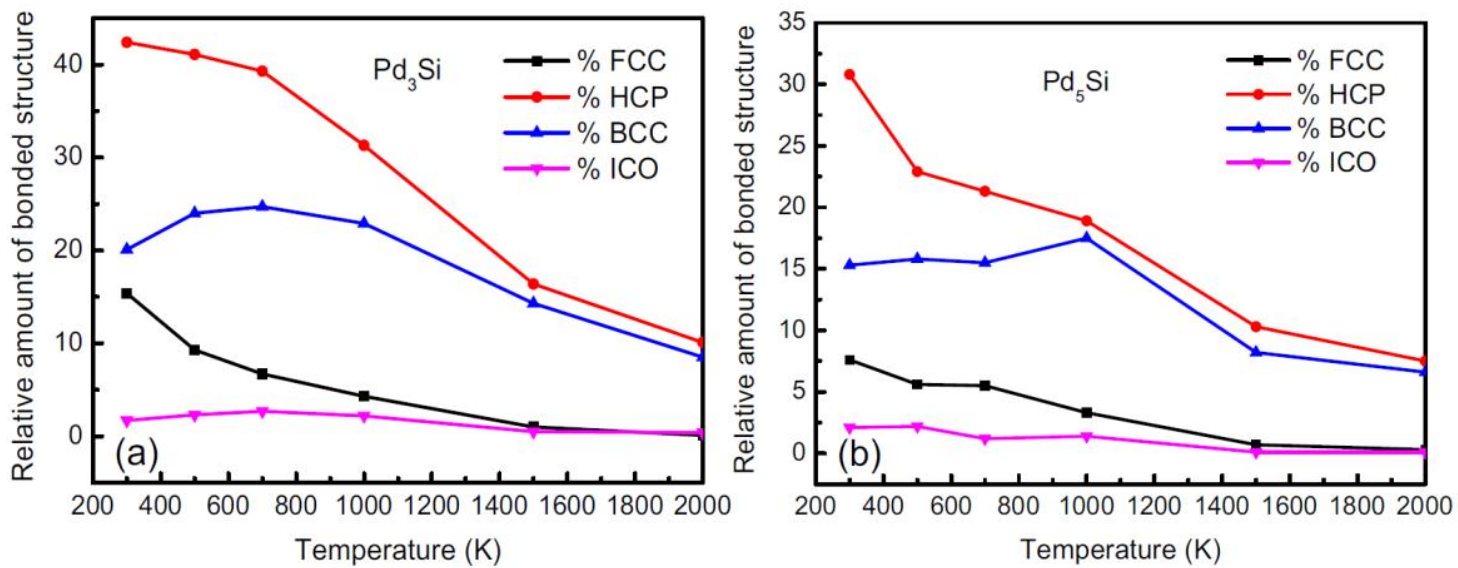

Fig. 22. The relative amount of bonded structure with temperatures for a) $\mathrm{Pd}_{3} \mathrm{Si}_{\mathrm{ICSD}}$ b) $\mathrm{Pd}_{5} \mathrm{Si}_{1 \mathrm{ISD}}$ during cooling from the melt.

\section{Conclusion}

In this work, the Quantum Sutton-Chen (Q-SC) potentials for molecular dynamic (MD) simulation were derived for the Pd-Si system for the first time. They were revealed to enable the reliable atomistic 
description of the metallic or intermetallic alloys in the binary system; including liquid-glass transition and associated glass formation, crystallisation, cluster and structural properties.

Pd-Si alloy melts are characterised by a sustained reduction in the diffusion coefficients of Pd and Si atoms during cooling, which is attributed to the evolution of atomic association for clustering in the undercooled liquid structure.

Overall, the glass formation ability is dictated by cluster evolution, which itself depends on the composition below the glass transition temperature. From a clustering point of view, $\mathrm{Pd}_{4} \mathrm{Si}$ and $\mathrm{Pd}_{5} \mathrm{Si}$ tend to offer more middle-range clustering (ordering) and hence a greater GFA. This is largely consistent with the reduced glass transition temperature as an indicator. These compositions are also next to the deepest eutectic valley in the Pd-Si system, which is another well-known feature for good glass formation alloys.

\section{References}

1. W. Klement, R.H. Willens, P. Duwez. Non-crystalline structure in solidified gold-silicon alloys. Nature, 187 (1960), pp. 869-870.

2. Editorial. Crystallizing glassy issues, Nat. Mater., 14 (2015), p. 541.

3. G. Shao. Prediction of amorphous phase stability in metallic alloys. J. Appl. Phys., 88 (2000), pp. 4443-4445.

4. F.H. Stillinger, A. Rahman. Improved simulation of liquid water by molecular dynamics. J. Chem. Phys., 60 (1974), p. 1545.

5. R. Car, M. Parrinello. Structural, Dymanical, and electronic properties of amorphous silicon: an ab initio molecular-dynamics study. Phys. Rev. Lett., 60 (1988), pp. 204-207.

6. P.J. Pinkerton. A Treatise on Rocks. White, Cochrane \& Company (1811).

7. S. Özdemir Kart, M. Tomak, M. Uludoğan, T. Çağın. Liquid properties of Pd-Ni alloys. J. Non-Cryst. Solids, 337 (2004), pp. 101-108.

8. Y. Qi, T. Çağın, Y. Kimura, W.A. Goddard III. Molecular-dynamics simulations of glass formation and crystallization in binary liquid metals: Cu-Ag and Cu-Ni. Phys. Rev. B, 59 (1999), p. 3527.

9. S. Özdemir Kart, M. Tomak, M. Uludoğan, T. ÇaĞın. Structural, thermodynamical, and transport properties of undercooled binary Pd-Ni alloys. Mater. Sci. Eng. A, 435 (2006), pp. 736-744.

10. J. Tersoif. New empirical approach for the structure and energy of covalent systems. Phys. Rev. B, 37 (1988), p. 11.

11. R. Takagi, A.K. Adya, K. Kawamura. Molecular dynamics simulation of amorphous Pd80Si20 alloy. Trans. Jpn. Inst. Metals, 28 (1987), pp. 761-764.

12. T. Ohkubo, Y. Hirotsu. Molecular dynamics simulation of local atomic structure in amorphous Pd-Si alloys. Mater. Sci. Eng. A, 217 (1996), pp. 388-391.

13. P.H. Gaskell. A new structural model for amorphous transition metal silicides, borides, phosphides and carbides. J. Non-Cryst. Solids, 32 (1979), pp. 207-224.

14. F.H. Stillinger, T.a. Weber. Computer simulation of local order in condensed phases of silicon. Phys. Rev. B, 31 (1985), pp. 5262-5271. 
15. I. Štich, R. Car, M. Parrinello. Amorphous silicon studied by ab initio molecular dynamics: preparation, structure, and properties. Phys. Rev. B, 44 (1991), Article 11092.

16. E. Ko, M. Jain, J.R. Chelikowsky. First principles simulations of SiGe for the liquid and amorphous states.J. Chem. Phys., 117 (2002), p. 3476.

17. J.K. Nørskov. Covalent effects in the effective-medium theory of chemical binding: hydrogen heats of solution in the 3D metals. Phys. Rev. B, 26 (1982), p. 2875.

18. M.S. Daw, M.I. Baskes. Embedded-atom method: derivation and application to impurities, surfaces, and other defects in metals. Phys. Rev. B, 29 (1984), p. 6443.

19. M.W. Finnis, J.E. Sinclair. A simple empirical N-body potential for transition metals. Philos. Mag. A, 50 (1984), pp. 45-55.

20. A.P. Sutton, J. Chen. Long-range Finnis-Sinclair potentials. Philos. Mag. Lett., 61 (1990), pp. 139-146.

21. H.H. Kart, M. Uludoğan, T. Çağın, M. Tomak. Simulation of crystallization and glass formation of binary PdAg metal alloys. J. Non-Cryst. Solids, 342 (2004), pp. 6-11.

22. R. Biswas, D.R. Hamann. Classical two and three-body interatomic potentials for silicon simulations, Proceedings of the MRS, Cambridge Univ Press (1985), p. 173.

23. J. Tersoff. New empirical model for the structural properties of silicon. Phys. Rev. Lett., 56 (1986), pp. 632635.

24. M.I. Baskes. Application of the embedded-atom method to covalent materials: a semiempirical potential for silicon. Phys. Rev. Lett., 59 (1987), p. 2666.

25. G. Kresse, J. Hafner. Ab initio molecular dynamics for liquid metals. Phys. Rev. B, 47 (1993), pp. 558-561.

26. H.J. Monkhorst, J.D. Pack. Special points for Brillouin-zone integrations. Phys. Rev. B, 13 (1976), pp. 51885192.

27. R. Gaudoin, W.M.C. Foulkes, G. Rajagopal. Ab initio calculations of the cohesive energy and the bulk modulus of aluminium. J. Phys. Condens. Matter, 14 (2002), p. 8787.

28. G. Shao. Melting of metallic and intermetallic solids: an energetic view from DFT calculated potential wells. Comput. Mater. Sci., 43 (2008), pp. 1141-1146.

29. W. Smith, T.R. Forester. The DL_POLY Package of Molecular Simulation Routines. Daresbury and Rutherford Appleton Laboratory, Daresbury, UK (1996).

30. H. Rafii-Tabar, A.P. Sulton. Long-range Finnis-Sinclair potentials for fcc metallic alloys. Philos. Mag. Lett., 63 (1991), pp. 217-224.

31. H.C. Andersen. Molecular dynamics simulations at constant pressure and/or temperature. J. Chem. Phys., 72 (1980), p. 2384.

32. M. Parrinello, A. Rahman. Crystal structure and pair potentials: a molecular-dynamics study. Phys. Rev. Lett., 45 (1980), p. 1196. (United States)

33. S. Nosé. A unified formulation of the constant temperature molecular dynamics methods. J. Chem. Phys., 81 (1984), p. 511. 
34. W.G. Hoover. Canonical dynamics: equilibrium phase-space distributions. Phys. Rev. A, 31 (1985), p. 1695.

35. M. Faruq, A. Villesuzanne, G. Shao. Structure, melting and transport properties of binary liquid Pd-Si metal alloys: molecular dynamics simulations. J. Mater. Phys. Chem., 5 (2017), pp. 20-31.

36. T. lida, R.I.L. Guthrie. The Physical Properties of Liquid Metals. Oxford Science Publications, Oxford (1988).

37. J. Ding, M. Xu, P.F. Guan, S.W. Deng, Y.Q. Cheng, E. Ma. Temperature effects on atomic pair distribution functions of melts. J. Chem. Phys., 140 (2014), Article 64501.

38. S. Özdemir Kart, M. Tomak, M. Uludoğan, T. Çağın. Molecular dynamics studies on glass formation of Pd-Ni alloys by rapid quenching. Turk. J. Phys., 30 (2006), pp. 319-327.

39. H.R. Wendt, F.F. Abraham. Empirical criterion for the glass transition region based on Monte Carlo simulations. Phys. Rev. Lett., 41 (1978), p. 1244.

40. G. Shao. Thermodynamic and kinetic aspects of intermetallic amorphous alloys. Intermetallics, 11 (2003), pp. 313-324.

41. H.S. Chen, D. Turnbull. Formation, stability and structure of palladium-silicon based alloy glasses. Acta Metall., 17 (1969), pp. 1021-1031.

42. P. Ballone, S. Rubini. Embedded-atom model of glass-forming Si-metal alloys. Phys. Rev. B, 51 (1995), Article 14962.

43. Z.P. Lu, C.T. Liu. A new glass-forming ability criterion for bulk metallic glasses. Acta Mater., 50 (2002), pp. 3501-3512.

44. G. Shao, B. Lu, Y.Q. Liu, P. Tsakiropoulos. Glass forming ability of multi-component metallic systems. Intermetallics, Elsevier (2005), pp. 409-414.

45. G.P. Tiwari, R.V. Ramanujan, M.R. Gonal, R. Prasad, P. Raj, B.P. Badguzar, et al. Structural relaxation in metallic glasses. Mater. Sci. Eng. A, 304 (2001), pp. 499-504.

46. H.S. Chen. Glassy metals. Rep. Prog. Phys., 43 (1980), p. 353.

47. Q.X. Pei, C. Lu, H.P. Lee. Crystallization of amorphous alloy during isothermal annealing: a molecular dynamics study. J. Phys. Condens. Matter, 17 (2005), p. 1493.

48. T. Abe, S. Akiyama, H. Onodera. Crystallization of sputter deposited amorphous Ti-52at\% Al alloy. ISIJ Int., 34 (1994), pp. 429-434

49. Y.Q. Cheng, E. Ma. Atomic-level structure and structure--property relationship in metallic glasses. Prog. Mater. Sci., 56 (2011), pp. 379-473.

50. A. Stukowski. Structure identification methods for atomistic simulations of crystalline materials. Model. Simul. Mater. Sci. Eng., 20 (2012), Article 45021.

51. J. Liu, J.Z. Zhao, Z.Q. Hu. The development of microstructure in a rapidly solidified Cu. Mater. Sci. Eng. A, 452-453 (2007), pp. 103-109. 